\title{
13
}

\section{Collection and Examination of a Municipal Separate Storm Sewer System Database}

Robert Pitt, Alex Maestre, Renee Morquecho, and Derek Williamson

The University of Alabama and the Center for Watershed Protection were awarded an EPA Office of Water 104(b)3 grant in 2001 to collect and evaluate stormwater data from a representative number of NPDES (National Pollutant Discharge Elimination System) MS4 (municipal separate storm sewer system) stormwater permit holders. The initial version of this database, the National Stormwater Quality Database (NSQD, version 1.0) is currently being completed. These stormwater quality data and site descriptions are being collected and reviewed to describe the characteristics of national stormwater quality, to provide guidance for future sampling needs, and to enhance local stormwater management activities in areas having limited data.

The monitoring data collected over nearly a $10-y$ period from more than 200 municipalities throughout the country have a great potential in characterizing the quality of stormwater runoff and comparing it against historical benchmarks. This project is creating a national database of stormwater monitoring data collected as part of the existing stormwater permit program, providing a scientific analysis of the data, and providing recommendations for improving the quality and management value of future NPDES monitoring efforts.

Pitt, R.E., A. Maestre, R. Morquecho and D. Williamson. 2004. "Collection and Examination of a Municipal Separate Storm Sewer System Database." Journal of Water Management Modeling R220-13. doi: 10.14796/JWMM.R220-13.

(C) CHI 2004 www.chijournal.org ISSN: 2292-6062 (Formerly in Innovative Modeling of Urban Water Systems. ISBN: 0-9683681-9-0) 
Each data set is receiving a quality assurance/quality control review based on reasonableness of data, extreme values, relationships among parameters, sampling methods, and a review of the analytical methods. The statistical analyses are being conducted at several levels. Probability plots are used to identify range, randomness and normality. Clustering and principal component analyses are utilized to characterize significant factors affecting the data patterns. The master data set is also being evaluated to develop descriptive statistics, such as measures of central tendency and standard errors. Regional and climatic differences are being tested, including the influences of land use, and the effects of storm size and season, among other factors. The data will be used to develop a method to predict expected stormwater quality for a variety of significant factors and will be used to examine a number of preconceptions concerning the characteristics of stormwater, sampling design decisions, and some basic data analysis issues. Some of the issues that are being examined with this data include:

- the occurrence and magnitude of first-flushes,

- the effects of different sampling methods (the use of grab sampling vs. automatic samplers, for example) on stormwater quality data,

- trends in stormwater quality with time,

- the effects of infrequent wrong data in large data bases,

- appropriate methods to handle values that are below detection limits, and

- the necessary sampling effort needed to characterize stormwater quality, for example.

This chapter describes the data collected to date and presents some preliminary data findings.

When this NSQD is completed (populated with most of the NPDES stormwater monitoring data), the continued collection of outfall stormwater quality data in the U.S. for basic characterization purposes may have limited use. Some communities may have obviously unusual conditions, or adequate data may not be available in their region. In these conditions, outfall monitoring may be needed. However, stormwater monitoring will continue to be needed for other purposes in many areas having, or anticipating, active stormwater management programs (especially when supplemented with other biological, physical, and hydrologic monitoring components). These new monitoring programs should be designed specifically for additional objectives, beyond basic characterization. These objectives may include receiving water assessments to understand local problems, source area monitoring to identify critical 
sources of stormwater pollutants, treatability tests to verify the performance of stormwater controls for local conditions, and assessment monitoring to verify the success of the local stormwater management approach (including model calibration and verification). In many cases, the resources being spent for outfall monitoring could be more effectively spent to better understand many of these other aspects of an effective stormwater management program.

\subsection{Project Description and Background}

The importance of this project is based on the scarcity of nationally summarized and accessible data from the existing U.S. EPA's NPDES stormwater permit program. There have been some local and regional data summaries, but little has been done with nationwide data. A notable exception is the Camp, Dresser, and McGee (CDM) national stormwater database (Smullen and Cave 2002) that combined historical Nationwide Urban Runoff Program (NURP) (EPA 1983), available urban U.S. Geological survey (USGS), and selected NPDES data. Their main effort has been to describe the probability distributions of these data (and corresponding EMCs, the event mean concentrations). They concluded that concentrations for different land uses were not significantly different, so all their data were pooled.

Between 1978 and 1983, the EPA developed NURP that examined stormwater quality from separate storm sewers in different land uses (EPA 1983). This project studied 81 outfalls in 28 communities throughout the U.S. and included the monitoring of approximately 2300 storm events. The data was presented for several land use categories, although most of the information was obtained from residential lands. Since NURP, other important studies have been conducted that characterize stormwater. The USGS created a database with more than 1100 storms from 98 monitoring sites in 20 metropolitan areas. The Federal Highway Administration (FHWA) analyzed stormwater runoff from 31 highways in 11 states during the 1970s and 1980s (Cave 1995). The city of Austin also developed a database havingmore than 1200 events (Smullen 2003).

Other regional databases also exist, mostly using local NPDES data. These include the Los Angeles area database, the Santa Clara and Alameda County (California) databases, the Oregon Association of Clean Water Agencies Database, and the Dallas, Texas, area stormwater database. These regional data are (or will be) included in the NSQD national database. However, the USGS or historical NURP data will not be included in the NSQD database due to lack of consistent descriptive information for the older drainage areas and because 
of the age of the data from those prior studies. Much of the NURP data is available in electronic form at the University of Alabama student American Water Resources Association web page at: http://www.eng.ua.edu/ awra/ download.htm. The results (especially the stormwater characteristic prediction procedures) from these other databases will be compared to similar findings from the final analyses using this expanded database to indicate any important differences.

Outside the U.S., there have been important efforts to characterize stormwater. In Toronto, Canada, the Toronto Area Watershed Management Strategy Study (TAWMS) was conducted during 1983 and 1984 and extensively monitored industrial stormwater, along with snowmelt in the urban area (Pitt and McLean 1986), for example. Numerous other investigations in South Africa, the South Pacific, Europe and Latin America have also been conducted over the past $30 \mathrm{y}$, but no large-scale summaries of that data have been prepared. About 3,500 international references on stormwater have been reviewed and compiled since 1996 by the Urban Wet Weather Flows literature review team for publication in Water Environment Research (Field, et al. 1997, 1998; O'Connor, et al. 1999; Fan, et al. 2000; Clark, et al. 2001, 2001, 2003). An overall compilation of these literature reviews is available at:

http://www.eng.ua.edu/ rpitt/Publications/Publications.shtml

The reviews include short summaries of the papers and are organized by major topics. Besides journal articles, many published conference proceedings are also represented (including the extensive conference proceedings from the $8^{\text {th }}$ International Conference on Urban Storm Drainage held in Sydney, Australia, in 1999, the $9^{\text {th }}$ International Conference on Urban Storm Drainage held in Portland, OR, in 2002, and the Toronto Stormwater and Urban Water Systems Modeling conference series, amongst many other specialty conferences).

The NSQD is unique in that detailed descriptions of the test areas and sampling conditions are also being collected, including aerial photographs and topographic maps that are being obtained from public domain Internet sources. Land use information used is as supplied by the communities submitting the data, although aerial photographs and maps are also used to help clarify questions concerning specific development characteristics. Most of the sites have homogeneous land uses, although many are mixed. These characteristics are all fully noted in the database.

Stormwater runoff data from existing NPDES permit applications and annual monitoring reports are being collected during this project. This project also includes extensive $\mathrm{QA} / \mathrm{QC}$ (quality assurance/quality control) evaluations 
of these data; and performing statistical analyses and summaries of these data. The final information will be published on the Internet (such as on an EPA OWOWM, Office of Water and Office of Wastewater Management, site and on the Center for Watershed Protection's SMRC, Stormwater Manager's Resources Center, site at: http://www.stormwatercenter.net/). Some of the information is currently located at Pitt's teaching and research web site at: http://www.eng.ua.edu/ rpitt/Research/ms $4 /$ mainms $4 . s h t m l$

The Phase I NPDES communities included areas with:

- a stormwater discharge from a MS4 serving a population of 250,000 or more (large system), or

- a stormwater discharge from a MS4 serving a population of 100,000 or more, but less than 250,000 (medium system).

More than 200 municipalities, plus numerous additional special districts and governmental agencies were included in this program. Part 2 of the NPDES discharge permit application specified that sampling was needed and that the following items were to be included in the application:

- proposed monitoring program for representative data collection during the term of the permit;

- quantitative data from 5 to 10 representative locations;

- estimates of the annual pollutant load and event mean concentration (EMC) of system discharges; and

- proposed schedule to provide estimates of seasonal pollutant loads and the EMC for certain detected constituents during the term of the permit.

The permit applications were due in 1992 and 1993. For Part 2 of the application, municipalities were to submit grab (for certain pollutants having severe holding time restrictions, such as bacteria) and flow-weighted sampling data from selected sites ( 5 to 10 outfalls) for three representative storm events at least one month apart. In addition, the municipalities musthave also developed programs for future sampling activities that specified sampling locations, frequency, pollutants to be analyzed, and sampling equipment.

Numerous constituents were to be analyzed, including typical conventional pollutants (TSS, TDS, COD, $\mathrm{BOD}_{5}$, oil and grease, fecal coliforms, fecal strep., $\mathrm{pH}, \mathrm{Cl}, \mathrm{TKN}, \mathrm{NO}_{3}, \mathrm{TP}$, and $\mathrm{PO}_{4}$ ), plus many heavy metals (including total forms of arsenic, chromium, copper, lead, mercury, and zinc, plus others), and numerous listed organic toxicants (including PAHs, pesticides, and PCBs). Many communities also analyzed samples for filtered forms of the heavy metals. This database currently includes information for about 125 different stormwater quality constituents, although the current database is 
mostly populated with data from 35 of the commonly analyzed pollutants (as summarized later in Table 13.1). Therefore, there has been a substantial amount of stormwater quality data collected during the past $10 \mathrm{y}$ throughout the U.S., although most of these data are not readily available, nor have detailed statistical analyses been conducted and presented.

\subsection{Data Collection and Analysis Efforts to Date}

As of mid-summer 2003, 3,770 separate events from 66 agencies and municipalities from 17 states have been collected and the data entered into NSQD. Figure 13.1 shows the locations of these municipalities on a national map. Excellent national coverage is anticipated, although there will be few municipalities from the northern, west-central states of Montana, Wyoming, and North and South Dakota (where cities are generally small, and few were included in the Phase 1 NPDES program). This current database (NSQD, Version 1.0) covers areas mostly in the southern, Atlantic, central, and western parts of the US. Anticipated future project phases will help extend the national coverage.

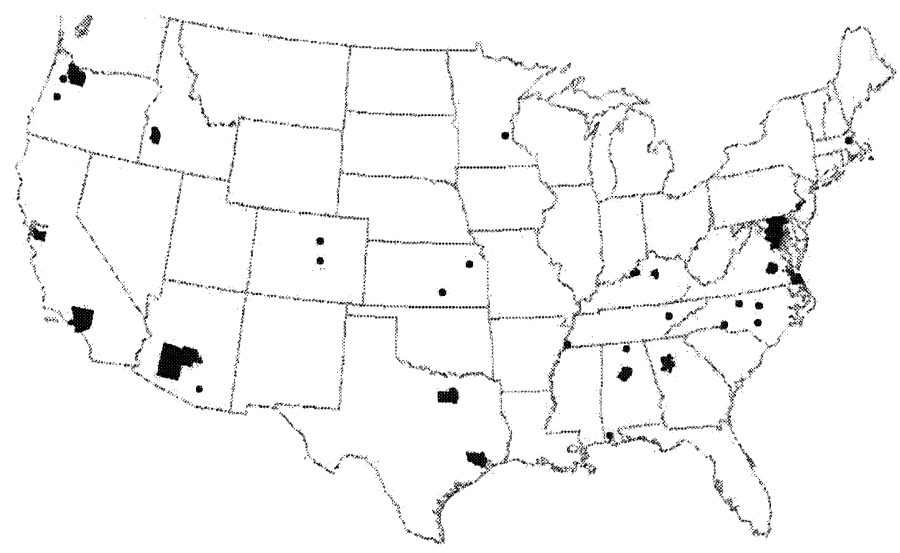

Figure 13.1 Communities from which data has been obtained and entered in the NSQD.

Some of the municipalities that have been contacted (and some in which data was received) have information that could not be used for various reasons. One of the most common reasons was that the samples had been collected from 
receiving waters (such as Washington state, Nashville, and Chattanooga). Only data from well-described stormwater outfall locations are being used for the database. These can be open channel outfalls in completely developed areas, but are more commonly conventional outfall pipes. The other major problem is that the sampling locations and/or the drainage areas were not described. Data with some missing information is being used for now, with the intention of obtaining the needed information later. However, there will likely still be some minor data gaps that will not be able to be filled. In addition, the list of constituents being monitored has varied for different locations. Most areas evaluated the common stormwater constituents, but few have included organic toxicants. The most serious gap is the frequent lack of runoff volume data, although all sites have included rain data. Finally, if all the data were collected that was requested, the current project resources will not permit their full utilization, as it requires a great deal of time to enter and review this information. About $10 \%$ of the collected data needed verification during the $\mathrm{QA} / \mathrm{QC}$ process. If that potentially faulty data remained in the database, spurious statistical analyses would have resulted. The collection and review of the data is a necessary first step to facilitate later analyses.

The assembled data was entered into NSQD, including site descriptions (state, municipality, land use components, and EPA rain zone), sampling information (date, season, rain depth, runoff depth, sampling method, sample type, etc.), and constituent measurements (concentrations, grouped in categories). In addition, more detailed site, sampling, and analysis information has been collected for most sampling sites and is also included as supplemental information. The reported land use information supplied by the communities is being used, with verification of some areas with aerial photographs and maps. In many cases, the sampled watersheds have multiple land uses and those designations are included in the database (the database lists the percentages of the drainage as residential, commercial, industrial, freeway, institutional, and open space). The final data analyses will consider these mixed sites also, especially for verification for the model development activities, although the following preliminary results are only for the homogeneous land use sites.

\subsubsection{Preliminary Summary of U.S. NPDES Phase 1 Stormwater Data}

Additional site information is being acquired to complete most of the missing records before the final data analyses. The following data and analysis descriptions should therefore be considered preliminary and will change with 
this additional data and analyses. However, this presentation only uses the most basic and robust analyses for preliminary consideration. The final report and data presentations will obviously be much more comprehensive.

Table 13.1 (see appendix at the end of the chapter) is a summary of the Phase 1 data collected and entered into the database as of mid-summer 2003. The data are separated into 11 land use categories: residential, commercial, industrial, institutional, freeways, and open space, plus mixtures of these land uses. Summaries are also shown for mixed land use areas (indicating the most prominent land use), and for the total data set combined. Only data having at least 50 total detected observations and at least 10 detected observations per land use category are shown on this table. The full database includes all of the data, obviously. In most cases, many more than these minimum numbers are available. The total number of observations and the percentage of observations above the detection limits are shown. However, some constituents were not monitored by very many stormwater permit holders, and some constituents were mostly all in the "not detected" category, and those data are not shown. As an example, filtered heavy metal observations, and especially organic analyses, have many fewer detected values than other constituents.

The total number of individual events included in the database is 3,770 , with most in the residential category $(1,069$ events). For most common constituents, detectable values are available for almost all monitored events. The median and coefficient of variation $(\mathrm{COV})$ values are only for those data having detectable concentrations. If the non-detected results were used in these calculations, extreme biases would invalidate many of the COV calculations. The final analyses will further examine issues associated with different detection limits, multiple laboratories, and varying analytical methods on the reported results and statistical analyses. Burton and Pitt (2002), and the many included references in that book, contains further discussions on these important issues.

Table 13.2 is a summary of methylene chloride and bis(2-ethylhexyl) phthalate, the most commonly reported and detected organic constituents. There were up to several hundred events that included $\mathrm{PAH}$ and pesticide data. The percentage of samples that had observable concentrations of these constituents ranged from 15 to $35 \%$, about the same detection rate as in previous stormwater investigations, such as Pitt, et al. 1995.

Statistical analyses are being conducted in stages. First, probability plots were used to identify range, randomness, and normality. Figure 13.2 is an example of log-normal probability plots for some of the constituents and for all data pooled. Probability plots shown as straight lines indicate that the 
concentrations can be represented by log-normal distributions. This is important as it indicates that data transformations, or the use of nonparametric statistical analyses, will be needed. Plots with obvious discontinuities imply that multiple data populations may be included. The future analyses will identify the significance of these different data categories (such as land use, region, and season).

Table 13.2. Summary of selected organic information in NSQD, version 1.0

\begin{tabular}{lcc}
\hline & $\begin{array}{c}\text { Methylene-chloride } \\
(\mu \mathrm{g} / \mathrm{L})\end{array}$ & $\begin{array}{c}\text { Bis(2-ethylhexyl) } \\
\text { phthalate }(\mu \mathrm{g} / \mathrm{L})\end{array}$ \\
\hline All Data Combined & & \\
Number of observations & 251 & 250 \\
\% of samples above detection & 36 & 30 \\
Median of detected values & 11.2 & 9.5 \\
Coefficient of variation & 0.77 & 1.13 \\
\hline
\end{tabular}
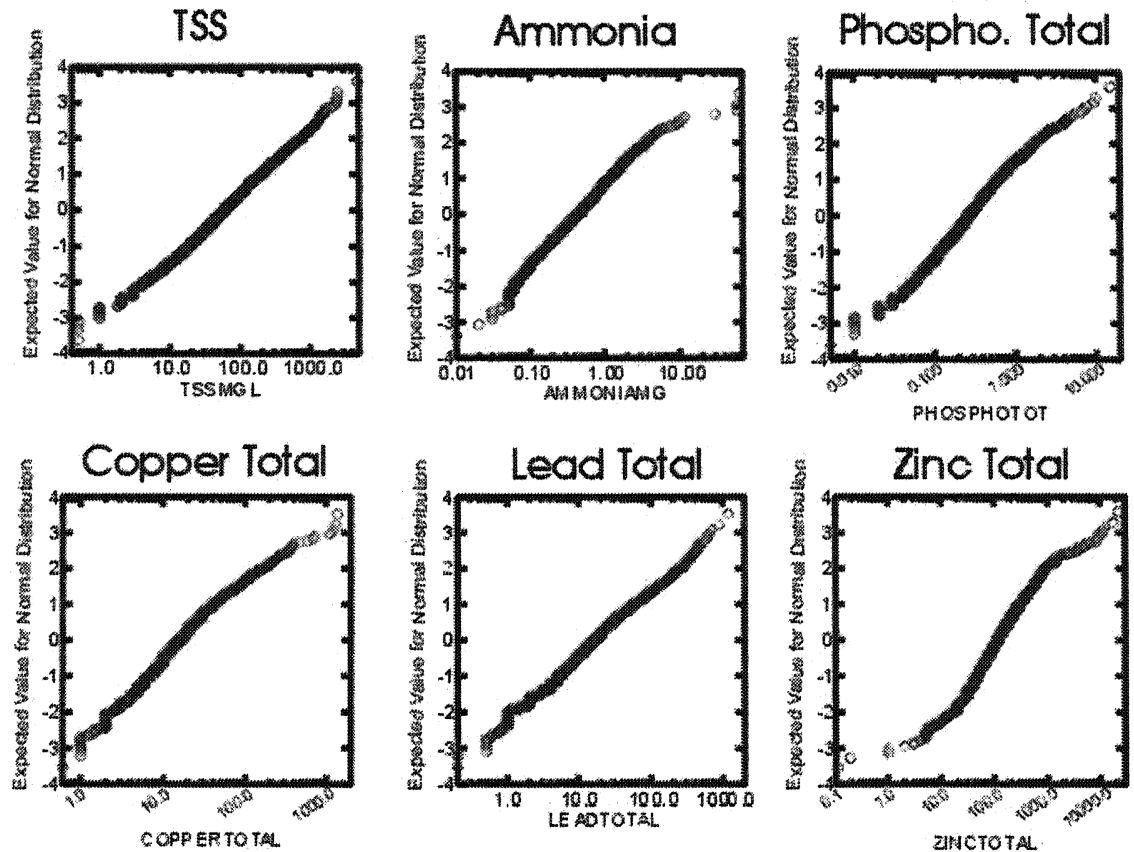

Figure 13.2. Log-normal probability plots of stormwater quality data for selected constituents. 


\subsubsection{Data Relationships}

The master data set will also be evaluated to develop descriptive statistics, such as measures of central tendency and standard errors. The runoff data will then be evaluated to determine which factors have a strong influence on event mean concentrations, including sampling methods. Tests for regional and climatic differences will be conducted, including the influences of land use and the effects of storm size, among other factors. Figure 13.3 includes example scatter plots of $\mathrm{COD}$ vs. $\mathrm{BOD}_{5}$, ammonia vs. TKN, filtered copper vs. total copper, and filtered zinc vs. total zinc, illustrating close relationships between these pairings, as expected.

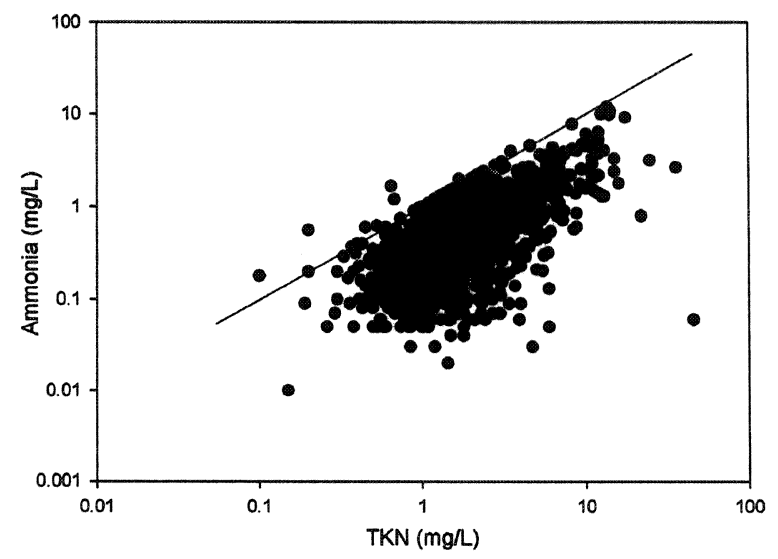

Figure 13.3a Ammonia vs TKN.

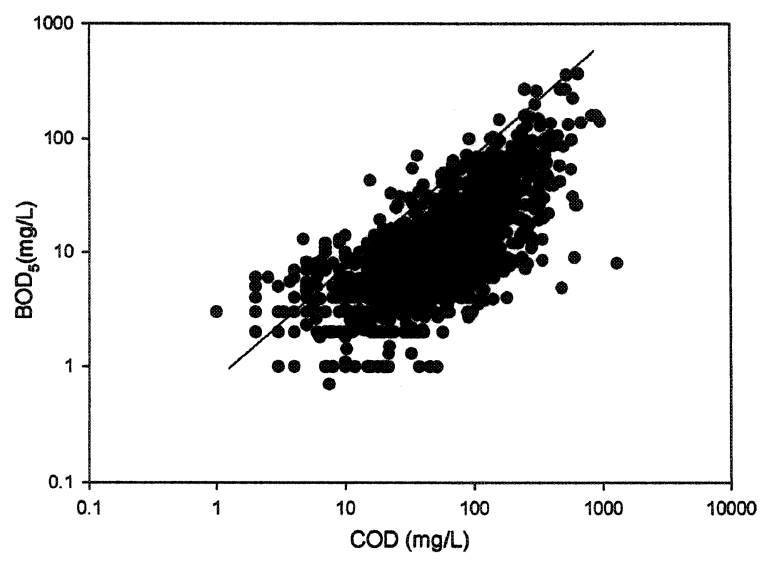

Figure 13.3a BOD vs COD 


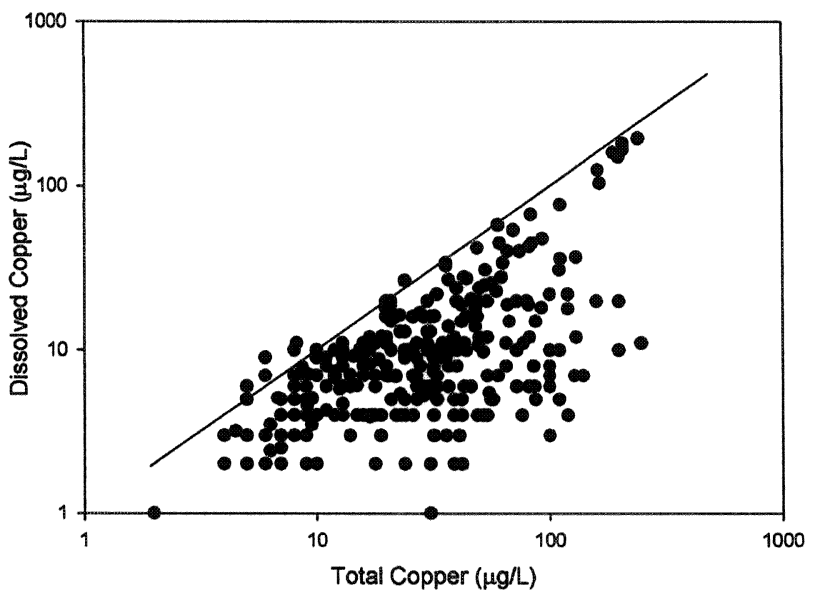

Figure 13.3b Total vs dissolved copper.

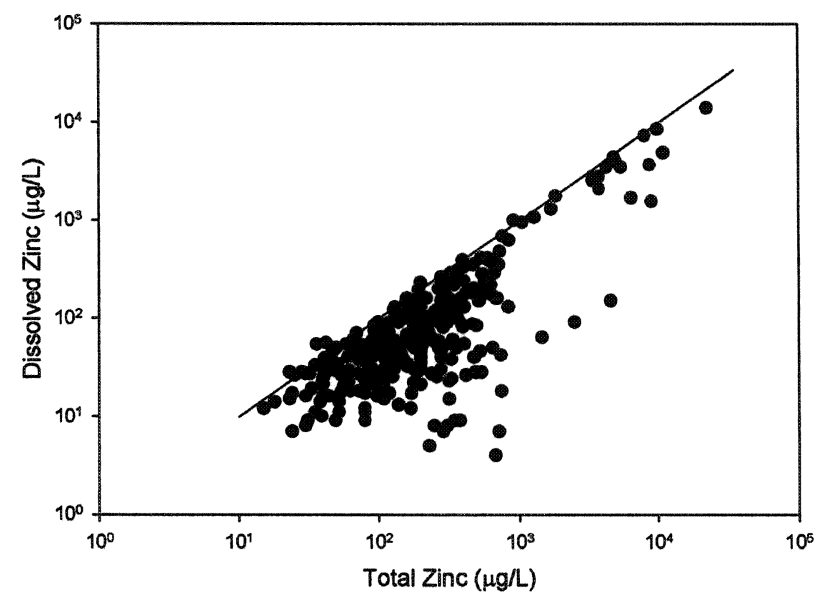

Figure 13.3b Total vs dissolved zinc.

Figure 13.4 shows scatter plots of suspended solids, phosphorus, fecal coliforms, and total zinc concentrations for different rain depths. Little variation of these concentrations with rain depth are seen when all of the data are combined, implyinglittle likelihood of important "first-flush" effects atstormwater outfall locations. If a first-flush was evident, one would expect higher concentrations associated with smaller rain depths (see Maestre, et al. 2003 for more detailed analyses of first-flush effects using the NSQD database information). 


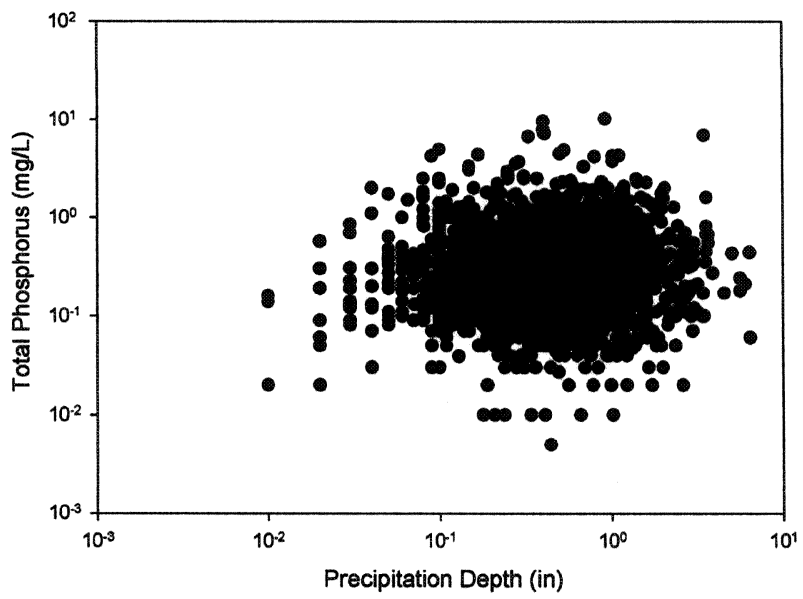

Figure 13.4a Total phosphorus vs precip. depth.

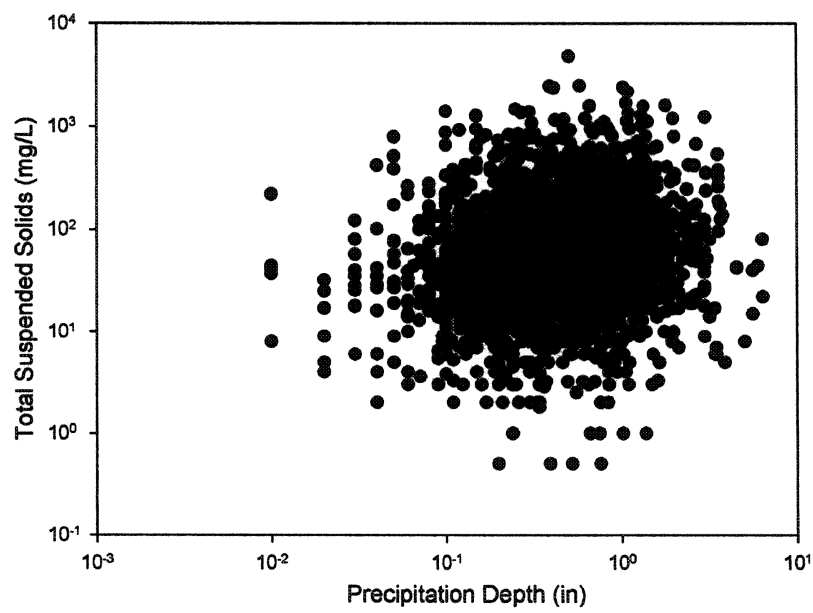

Figure 13.4a TSS vs precip. depth.

Figure 13.5 contains examples of grouped box and whisker plots for several constituents for different major land use categories. The TKN, plus copper, lead, and zinc observations are lowest for open space areas, while the freeway locations generally had the highest median values, except for phosphorus, nitrates, fecal coliforms, and zinc. The industrial sites had the highest 


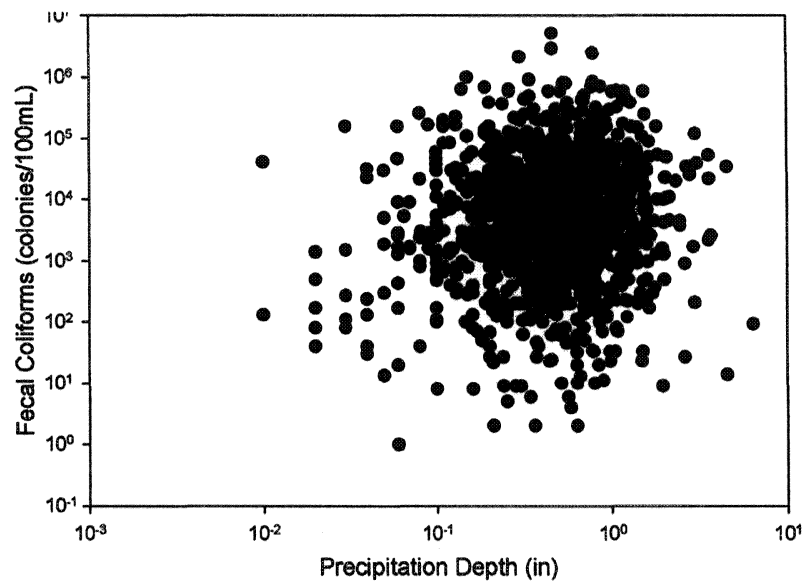

Figure 13.4b Fecal coliforms vs precip. depth.

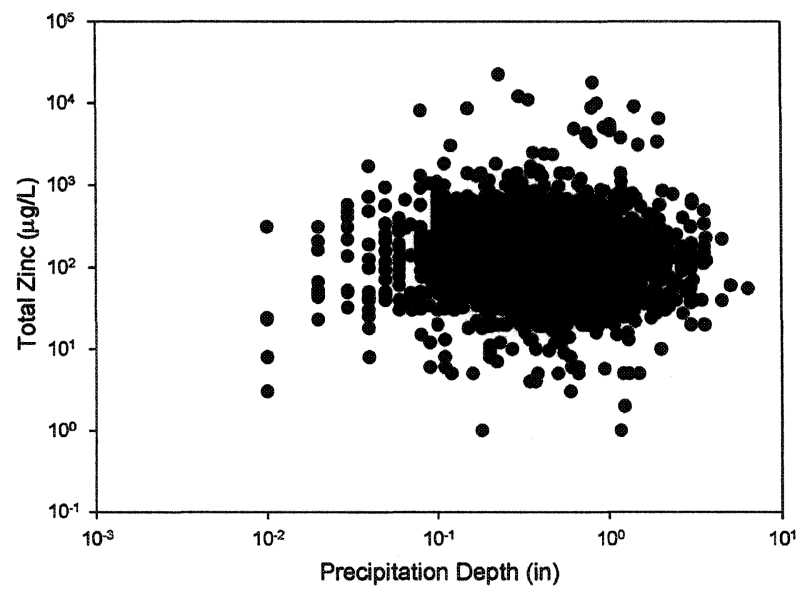

Figure 13.4b Total zinc vs precip. death.

reported zinc concentrations. Preliminary statistical ANOVA analyses for all land use categories (using SYSTAT) found significant differences for land use categories for all pollutants. The final analyses will further investigate this important finding and will also examine possible confounding factors. 


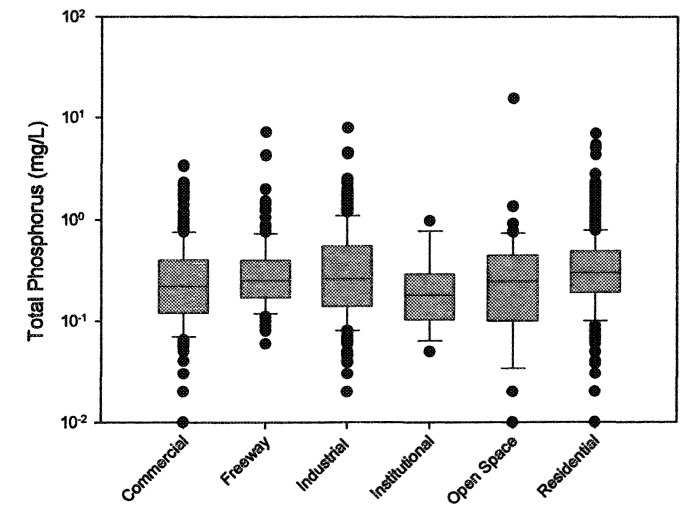

Figure 13.5a Total phosphorus.

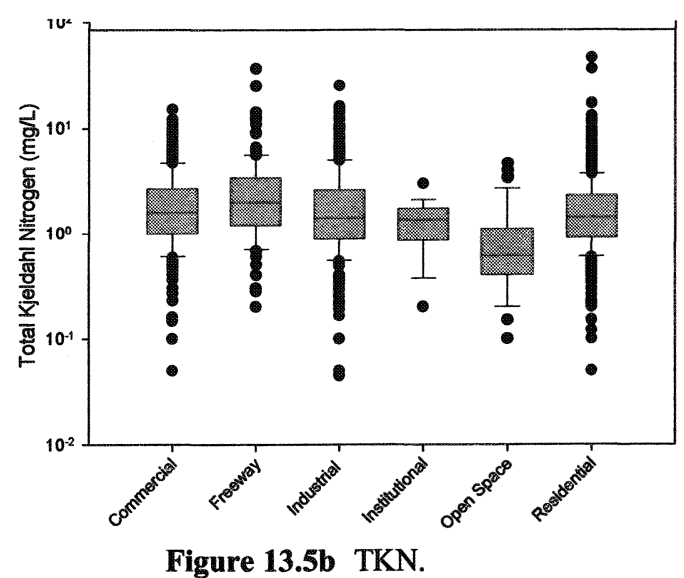

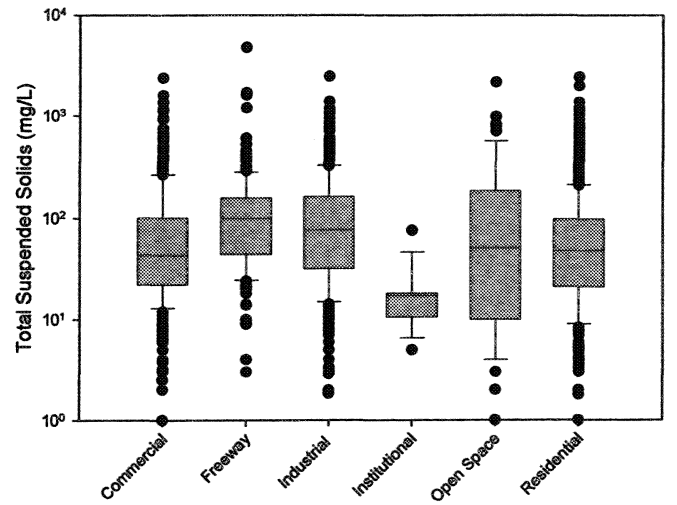

Figure 13.5a TSS.

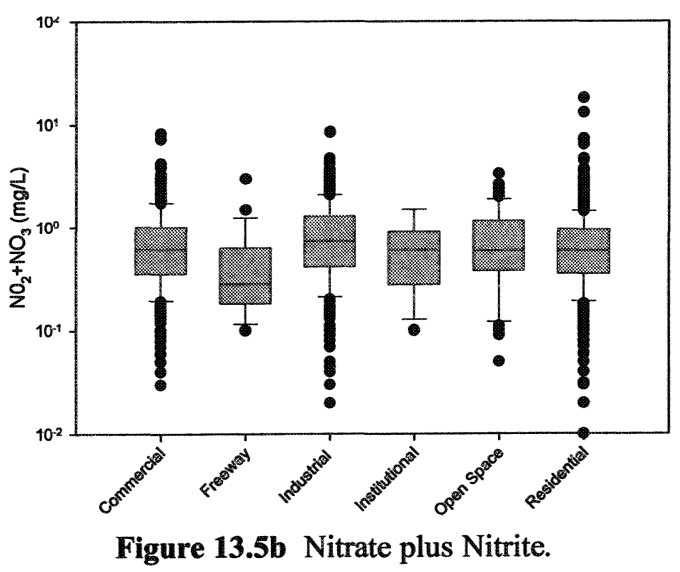

ํㅣㄴ

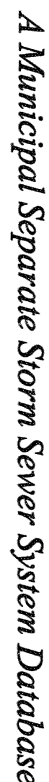




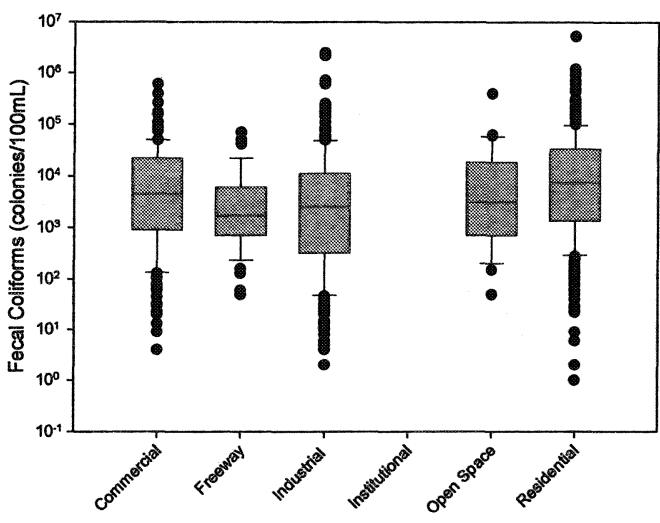

Figure 13.5c Fecal coliforms.

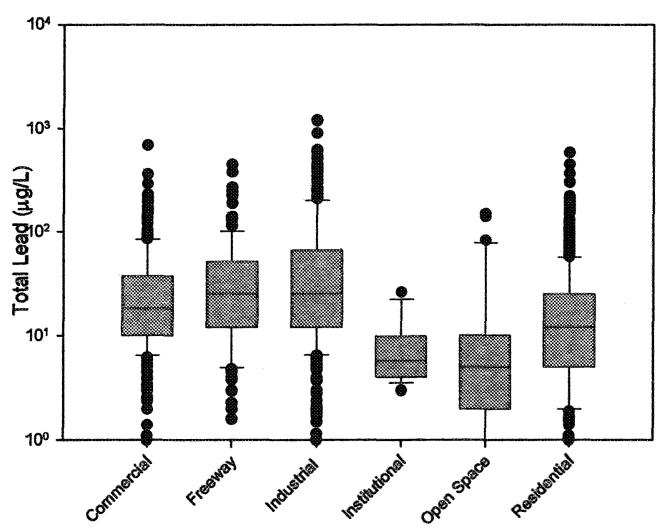

Figure 13.5d Total lead.

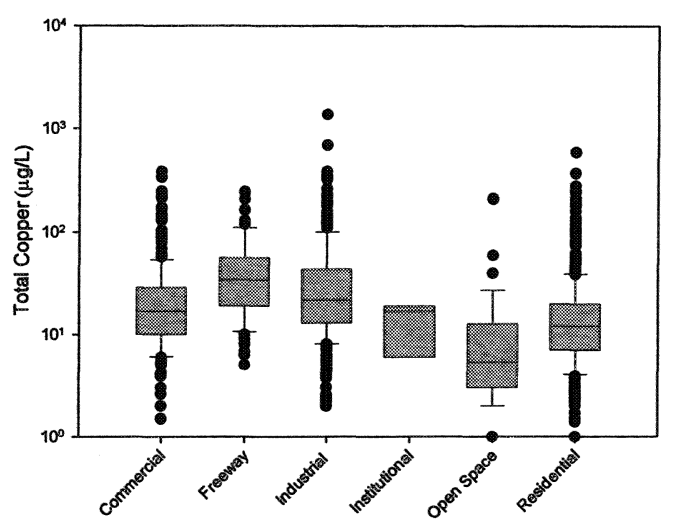

Figure 13.5c Total copper.

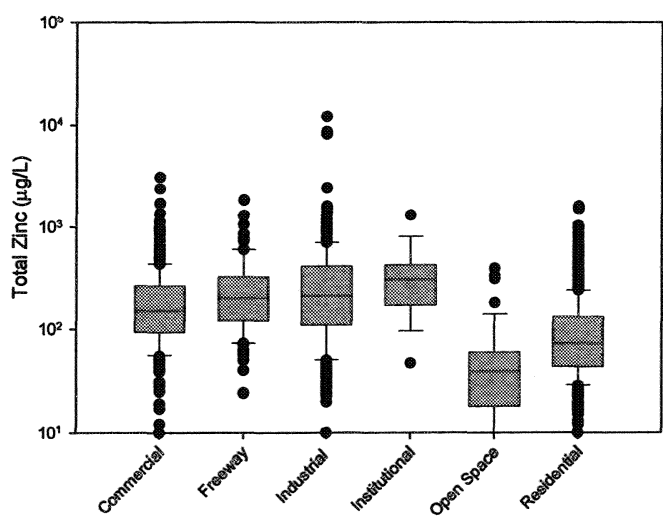

Figure 13.5d Total zinc. 

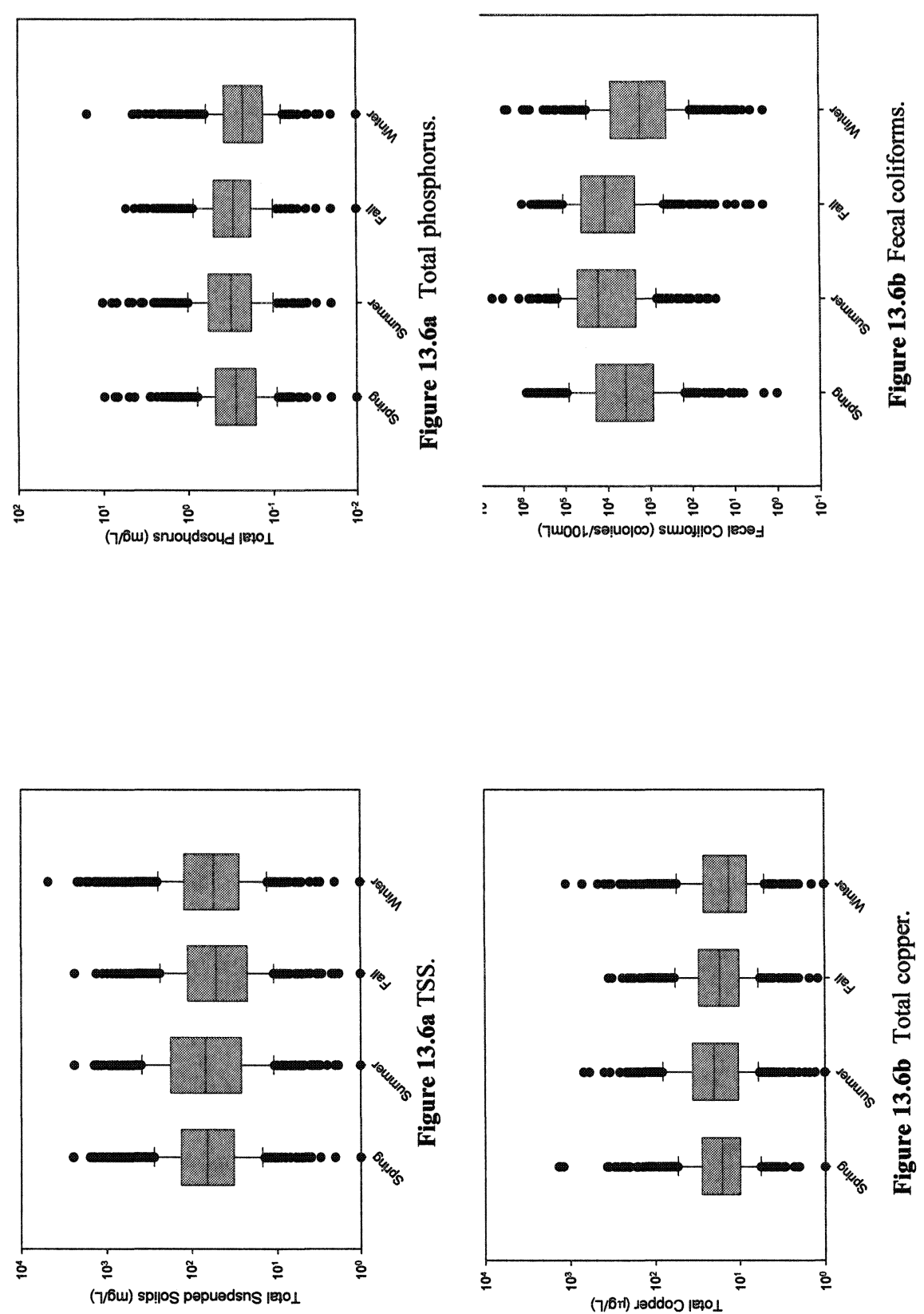
The seasonal variations for the example residential data shown in Figure13.6 are not as obvious, except that the bacteria values appear to be lowest during the winter season and highest during the summer and fall (a similar conclusion was obtained during the NURP, EPA 1983, data evaluations). The database contains no snowmelt data, so all the data corresponds to rain-related runoff.

Figure 13.7 presents example plots for selected residential area data for different EPA rain zones for the country. Zones 3 and 7 (the wettest areas of the country) had the lowest concentrations for most of the constituents.

Trends of concentrations with time will also be examined. A classical example is for lead, which would be expected to decrease over time with the increasing use of unleaded gasoline. Older stormwater samples from the 1970s typically had lead concentrations of about $100 \mu \mathrm{g} / \mathrm{L}$, or higher, while most current data indicate lead concentrations in the range of 1 to $10 \mu \mathrm{g} / \mathrm{L}$.

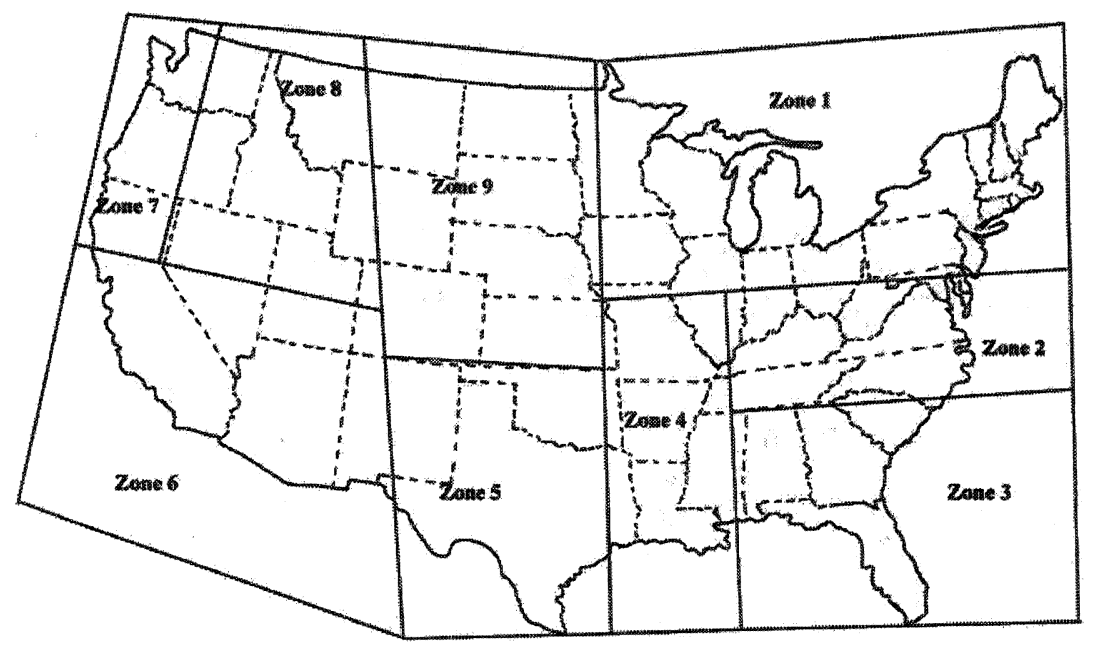

Figure 13.7 EPA rain zones.

\subsection{Sampling Guidance for Stormwater Monitoring}

A number of sampling issues can be statistically investigated using the information contained in the NSQD. The following discussion is a summary of the types of monitoring guidance that can be developed and refined using the database information. 


\subsubsection{Numbers of Samples Needed}

An important aspect of any research is the assurance that the samples collected represent the conditions to be tested and that the number of samples to be collected are sufficient to provide statistically relevant conclusions. An experimental design process can be used that estimates the number of needed samples based on the allowable error, the variance of the observations, and the degree of confidence and power needed for each parameter. The number of samples needed is therefore dependent on the objectives of the data (characterization, comparison, trends, etc.), the variation of the concentrations in the category being investigated (typically described by the coefficient of variation, or the ratio of the mean to the standard deviation), and the allowable errors (the confidence and the power).

A basic equation that can be used to estimate the number of samples to characterize a set of conditions (given in Burton and Pitt 2001) is as follows:

$$
n=\left[\operatorname{COV}\left(Z_{1-\alpha}+Z_{1-\beta}(\text { error })\right]^{2}\right.
$$

where:

$$
\begin{aligned}
& n=\text { number of samples needed } \\
& \alpha=\text { false positive rate (1- } \alpha \text { is the degree of confidence. } \mathrm{A}
\end{aligned}
$$




$$
\begin{aligned}
\mathrm{COV}= & \text { coefficient of variation (sometimes noted as CV), the } \\
& \text { standard deviation divided by the mean (Data set } \\
& \text { assumed to be normally distributed.) }
\end{aligned}
$$

This equation assumes a normal distribution of the data, which would require a $\log$ transformation of most stormwater quality data. If an allowable error of about $25 \%$ is desired and the COV is estimated to be 0.4 , then about 20 samples would have to be analyzed. The samples could be composited and a single analysis conducted, but this would not allow the COV assumption to be confirmed, or the actual confidence range of the concentration to be determined. The use of stratified random sampling can usually be used to advantage by significantly reducing the $\mathrm{COV}$ of the sub-population in the strata, requiring fewer samples for characterization.

Typical Numbers of Samples Needed for a Basic Stormwater Monitoring Program

The COV values for many constituents shown in Table 13.1 for the NPDES database range from unusually low values of about 0.1 (for $\mathrm{pH}$ ) to highs between 1 and 2. There are a few COV values that are larger. One objective of a data analysis procedure is to categorize the data into separate stratifications, each having small variations in the observed concentrations. The only stratification in Table 13.1 is land use. However, Figure 13.6 shows some differences by season and Figure 13.7 shows many differences by geographical area. It is expected that the final data analyses for this project will identify separate stratifications of data (possibly considering the combination of land use, geographical area, and season factors) to significantly reduce the variations in each category. It is expected that COV values in the range of 0.5 to 1.0 will be common for many of these data stratifications. With a reasonable confidence of $95 \%(\alpha=0.05)$ and power of $80 \%(\beta=0.20)$, and a common allowable error of $25 \%$, the number of samples needed to characterize conditions would likely range from about 25 to 50 . If only 12 samples are obtained for each category (strata), the allowable errors would range from about $50 \%$ to $100 \%$. Burton and Pitt (2001) present many additional experimental design equations and plots for other data quality objectives, including the effects of log transforming the data for more appropriate sampling effort approximations. In many cases, the actual errors in presenting data are larger than expected, due to relatively small numbers of samples. A continuing monitoring program (such as the Phase I stormwater NPDES permit monitoring effort) will result in better data as more samples are obtained with time. 


\subsubsection{Detection Limits of Analytical Methods}

The NSQD can also be useful when selecting analytical methods. There are many important factors that must be considered when selecting an analytical method (availability, cost, detection limit, repeatability, safety and disposal problems, comparisons with historical data, etc.), but the detection limit is likely most important when ensuring the suitability of the data. In many cases, analytical methods are used that have detection limits that are larger than a criterion value, making accurate exceedence frequencies impossible (Burton and Pitt 2001).

Environmental researchers need to be concerned with many attributes of numerous analytical methods when selecting the most appropriate methods to use for analyses of their samples. The main factors that affect the selection of an analytical method include: cost, reliability (the data quality objectives, or DQO which includes sensitivity, selectivity, repeatability), and safety. Most of these issues are not well documented in the literature for environmental sample analyses. Aspects of analytical reliability have received the most attention in the literature, but most of the other aspects noted above have not been adequately discussed for the many analytical alternatives available. It is difficult for a water quality analyst to decide which methods to select, or even if a choice exists.

The selection of the appropriate analysis procedure is dependent on the use of the data and how false negatives or false positives would affect water use decisions or regulatory questions. The QA objectives for the method detection limit (MDL) and precision (RPD) for the compounds of interest have been shown to be a function of the anticipated median concentrations in the samples (Pitt, et al. 1993). The MDL objectives should generally be about 0.25 , or less, of the median value for sample sets having typical concentration variations (COV values ranging from 0.5 to 1.25 ), based on many Monte Carlo evaluations to examine the rates of false negatives and false positives. Table 13.3 lists the typical median stormwater runoff constituent concentrations and the associated calculated MDL goals, for a typical stormwater monitoring project.

Using analytical methods having these detection limits, at least, will result in relatively few "non-detected" values. In most cases, analytical methods are available that can easily meet these goals. However, common problems are associated with some of the heavy metals, as most modern laboratories use ICP (inductively-coupled plasma) instruments that are capable of analyzing a broad range of metals simultaneously, but may not be able to meet these detection limit goals. When dissolved forms of the heavy metals need to be analyzed, the detection limits must be much smaller. 
Table 13.3. Example QA objectives for a stormwater characterization project.

\begin{tabular}{|c|c|c|c|c|}
\hline Constituent & Units & $\begin{array}{l}\text { Typical } \\
\text { COV } \\
\text { category }\end{array}$ & $\begin{array}{l}\text { Typical } \\
\text { Median } \\
\text { Conc. }\end{array}$ & $\begin{array}{l}\text { Estimated } \\
\text { MDL Goal }\end{array}$ \\
\hline $\begin{array}{l}\text { Turbidity } \\
\text { COD } \\
\text { suspended solids } \\
\text { nitrates } \\
\text { chromium } \\
\text { copper } \\
\text { lead } \\
\text { nickel } \\
\text { zinc } \\
\text { 1,3-dichlorobenzene } \\
\text { benzo(a) anthracene } \\
\text { bis(2-ethylhexyl) phthalate } \\
\text { butyl benzyl phthalate } \\
\text { fluoranthene } \\
\text { pentachlorophenol } \\
\text { pyrene } \\
\text { lindane and chlordane }\end{array}$ & $\begin{array}{l}\mathrm{NTU} \\
\mathrm{mg} / \mathrm{L} \\
\mathrm{mg} / \mathrm{L} \\
\mathrm{mg} / \mathrm{L} \\
\mu \mathrm{g} / \mathrm{L} \\
\mu \mathrm{g} / \mathrm{L} \\
\mu \mathrm{g} / \mathrm{L} \\
\mu \mathrm{g} / \mathrm{L} \\
\mu \mathrm{g} / \mathrm{L} \\
\mu \mathrm{g} / \mathrm{L} \\
\mu \mathrm{g} / \mathrm{L} \\
\mu \mathrm{g} / \mathrm{L} \\
\mu \mathrm{g} / \mathrm{L} \\
\mu \mathrm{g} / \mathrm{L} \\
\mu \mathrm{g} / \mathrm{L} \\
\mu \mathrm{g} / \mathrm{L} \\
\mu \mathrm{g} / \mathrm{L}\end{array}$ & $\begin{array}{l}\text { low } \\
\text { medium } \\
\text { medium } \\
\text { low } \\
\text { medium } \\
\text { medium } \\
\text { medium } \\
\text { medium } \\
\text { medium } \\
\text { medium } \\
\text { medium } \\
\text { medium } \\
\text { medium } \\
\text { medium } \\
\text { medium } \\
\text { medium } \\
\text { medium }\end{array}$ & $\begin{array}{l}5 \\
50 \\
50 \\
0.6 \\
7 \\
15 \\
15 \\
10 \\
100 \\
10 \\
30 \\
10 \\
15 \\
6 \\
10 \\
5 \\
1 \\
\end{array}$ & $\begin{array}{l}4 \\
12 \\
12 \\
0.4 \\
1.5 \\
3.5 \\
3.5 \\
2.3 \\
23 \\
2 \\
8 \\
2.3 \\
3 \\
1.4 \\
2 \\
1 \\
0.2\end{array}$ \\
\hline $\begin{array}{l}\text { COV value: } \\
<0.5 \text { (low) } \\
0.5 \text { to } 1.25 \text { (medium) } \\
>1.25 \text { (high) }\end{array}$ & & Multiplier & $\begin{array}{l}\mathrm{MDL} \\
3 \\
2\end{array}$ & \\
\hline
\end{tabular}

The NPDES stormwater database can be used to indicate the likely concentrations of interest for conditions similar to those that will be monitored. These expected values are a good start in determining the needed detection limits.

\subsubsection{Sampling Methods}

Details for all monitoring locations are desired for the database. Basic information (land use, season, geographic location, and if the sample is a first-flush or a composite sample) is available for all events in NSQD, and relatively complete site and monitoring descriptions are available for about one third of the events. This data includes sampling methods (automatic samplers vs. manual samplers; manufacture and model of sampler; etc.). Investigations of how these factors may influence the monitoring results will be made, as illustrated in the initial evaluation of first-flush vs. composited samples. The effects of automatic vs. 
manual sampling will also be examined when sufficient information has been collected. One example of a previous investigation on stormwater sampling methods was conducted by Roa-Espinosa and Bannerman (1995). They collected samples from five industrial sites using different monitoring methods. They concluded that many time-composited subsamples combined for a single analysis can provide improved accuracy compared to fewer samples associated with flow-weighted samplers, and especially compared to samples only taken during a portion of an event.

\subsection{Conclusions}

A major goal of this project is to provide guidance to stormwater managers and regulators. Especially important will be the use of this data as an updated benchmark for comparison with locally collected data. These comparisons will enable local monitoring data to be compared to typical values that should be expected for similar situations. If the local stormwater quality is significantly worse than expected, then it may be possible to quantify a treatment goal that should be attainable. In addition, this data may be useful for preliminary calculations when using the "simple method" for predicting mass discharges for unmonitored areas. This data can also be used as guidance when designing local stormwater monitoring programs (Burton and Pitt 2002), especially when determining the needed sampling effort based on expected variations. The final data analyses will expand on these preliminary examples and will also investigate other stormwater data and sampling issues.

\subsubsection{Suggested Role for Continued Stormwater Monitoring}

The current data and information contained in NSQD indicates the potential value that a completed database (containing most of the NPDES stormwater data) can provide. The excellent U.S. national coverage, along with the broad representation of land uses, seasons, and other factors, makes this information highly valuable for numerous basic stormwater management needs. Monitoring with no specific objective, except for general characterization in an area, is not likely to provide any additional value beyond the data and information contained in NSQD. After a sufficient amount of data has been collected by a Phase 1 community for representative land uses and other conditions, outfall characterization monitoring resources should be re-directed to other specific data collection and evaluation needs. Burton and Pitt (2001) provide much additional 
information on determining an adequate outfall monitoring program. Similarly, communities that have not initiated a stormwater monitoring program (such as the Phase II NPDES small communities) may not require general characterization monitoring (monitoring is not specifically required as part of the Phase II regulations), if they can identify a regional $\mathrm{Phase}$ I community that has compiled extensive monitoring data as part of their required NPDES stormwater permit. Obviously, there will be some situations that are not well represented in NSQD and additional characterization monitoring may be warranted. These situations will be identified in the final data analyses.

This is not to say that stormwater quality monitoring has no role as part of a stormwater management program. Burton and Pitt (2001) present extensive examples and procedures showing the importance of a balanced monitoring program. This publication is available from CRC Press, and a version is available at:

http://civil.eng.ua.edu/ rpitt/Publications/BooksandReports/Stormwater Effects Handbook by Burton and Pitt book/MainEDFS_Book.html

Stormwater quality monitoring is a crucial component of local programs. Specific objectives for these include:

- Receiving water assessments to understand local problems. Receiving water monitoring is needed to identify local problems, especially when identifying beneficial use impairments. Assimilative capacity calculations (TMDLs) require knowledge of local source discharges. The NSQD data and information can be used for preliminary designs and cost estimates, but it is also important to invest a small amount of resources to accurately determine local discharge conditions before expensive controls are designed.

- Source area monitoring to identify critical sources. In many cases, source area controls may be more cost-effective than regional controls. The identification of critical source areas is therefore needed as part of a comprehensive stormwater management program. Monitoring within a critical drainage area should be conducted to identify the sources of pollutants, while simultaneous outfall monitoring is needed to verify these source area measurements.

- Treatability tests to verify performance of stormwater controls for local conditions. In areas where stormwater controls are being installed, local measurements of performance are a good investment. Before and after monitoring, or parallel monitoring, 
is usually needed to measure the performance of many types of stormwater controls. The ASCE National Stormwater BMP database (http://www.bmpdatabase.org/) is a good place to start in predicting the performance of controls, but site-specific validations in an area where the controls have not been previously used should be conducted.

- Assessment monitoring to verify success of stormwater management approach. Stormwater quality monitoring is a critical component of an assessment monitoring effort. Receiving water monitoring needs to focus on beneficial use impairments, and associated chemical, physical, and biological monitoring. In many cases, source area or outfall controls are being used as part of comprehensive management programs. Therefore, outfall monitoring may also be needed.

\subsection{Appendix}

Table 13.1, which follows, was referenced on pages 262 and 264 in sections 13.1 and 13.2.

\section{Acknowledgments}

Many people and institutions need to be thanked for their help on this research project. Project support and assistance from Bryan Rittenhouse, the US EPA project officer for the Office of Water, is gratefully acknowledged. The many municipalities who worked with us to submit data and information were obviously crucial and the project could not be conducted without their help. Finally, the authors would like to thank a number of graduate students at the University of Alabama (especially Veera Rao Karri, Sanju Jacob, Sumandeep Shergill, Yukio Nara, and Soumya Chaturvedula) and employees of the Center for Watershed Protection (Ted Brown, Chris Swann, Karen Cappiella, and Tom Schueler) for their careful work on this project.

Ed. Note: References follow Table 13.1, starting on page 293. 
Table 13.1. Summary of available stormwater data included in NSQD, version 1.0

\begin{tabular}{|c|c|c|c|c|c|c|}
\hline \multirow[b]{2}{*}{ Overall Summary (3770) } & \multirow[t]{2}{*}{$\begin{array}{c}\text { Area } \\
\text { (acres) }\end{array}$} & $\begin{array}{l}\% \\
\text { Imperv. } \\
\end{array}$ & $\begin{array}{l}\text { Precip. } \\
\text { Depth } \\
\text { (in) }\end{array}$ & \multicolumn{2}{|c|}{$\begin{array}{l}\text { Runoff Cond. } \\
\text { Depth } \quad \text { (uS/cm } \\
\left.\text { (in) } \quad @, 25^{\circ} \mathrm{C}\right) \\
\end{array}$} & $\begin{array}{l}\text { Hardness } \\
(\mathrm{mg} / \mathrm{L} \mathrm{CaCO} 3)\end{array}$ \\
\hline & & & & & & \\
\hline Number of observations & 3756 & 2185 & 3187 & 1446 & 688 & 1083 \\
\hline$\%$ of samples above detection & 100 & 100 & 100 & 100 & 100 & 98.6 \\
\hline Median & 56.0 & 54.3 & 0.47 & 0.18 & 120 & 38.0 \\
\hline Coefficient of variation & 3.6 & 0.4 & 1.0 & 2.0 & 1.8 & 1.4 \\
\hline \multicolumn{7}{|l|}{ Residential (1069) } \\
\hline Number of observations & 1066 & 647 & 906 & 418 & 107 & 250 \\
\hline$\%$ of samples above detection & 100 & 100 & 100 & 100 & 100 & 100 \\
\hline Median & 57.3 & 37.0 & 0.46 & 0.12 & 96 & 32.0 \\
\hline Coefficient of variation & 4.7 & 0.4 & 1.0 & 1.9 & 1.5 & 1.0 \\
\hline \multicolumn{7}{|l|}{ Mixed Residential (615) } \\
\hline Number of observations & 612 & 277 & 438 & 217 & 106 & 157 \\
\hline$\%$ of samples above detection & 100 & 100 & 100 & 100 & 100 & 98.1 \\
\hline Median & 150.8 & 44.9 & 0.55 & 0.18 & 115 & 39.7 \\
\hline Coefficient of variation & 2.1 & 0.3 & 0.8 & 1.4 & 1.2 & 1.2 \\
\hline \multicolumn{7}{|l|}{ Commercial (497) } \\
\hline Number of observations & 497 & 258 & 415 & 134 & 66 & 139 \\
\hline$\%$ of samples above detection & 100 & 100 & 100 & 100 & 100 & 100 \\
\hline Median & 38.8 & 83.0 & 0.39 & 0.23 & 119 & 38.9 \\
\hline Coefficient of variation & 1.2 & 0.1 & 1.0 & 1.2 & 1.0 & 1.1 \\
\hline \multicolumn{7}{|l|}{ Mixed Commercial (303) } \\
\hline Number of observations & 303 & 237 & 276 & 106 & 40 & 80 \\
\hline$\%$ of samples above detection & 100 & 100 & 100 & 100 & 100 & 98.8 \\
\hline Median & 75.0 & 60.0 & 0.47 & 0.35 & 103 & 35.0 \\
\hline Coefficient of variation & 2.1 & 0.3 & 0.9 & 1.1 & 0.6 & 1.8 \\
\hline \multicolumn{7}{|l|}{ Industrial (524) } \\
\hline Number of observations & 524 & 317 & 436 & 202 & 108 & 138 \\
\hline$\%$ of samples above detection & 100 & 100 & 100 & 100 & 100 & 96.4 \\
\hline Median & 39.0 & 75.0 & 0.49 & 0.14 & 136 & 39.0 \\
\hline Coefficient of variation & 1.6 & 0.3 & 1.0 & 2.7 & 1.3 & 1.5 \\
\hline
\end{tabular}


Table 13.1. Summary of available stormwater data included in NSQD, version 1.0 (continued)

\begin{tabular}{|c|c|c|c|c|c|c|c|}
\hline \multirow[b]{2}{*}{ Overall Summary (3770) } & \multirow[t]{2}{*}{$\begin{array}{l}\text { Oil and } \\
\text { Grease } \\
(\mathrm{mg} / \mathrm{L})\end{array}$} & $\mathrm{pH}$ & $\begin{array}{l}\text { Temp. } \\
\text { (C) }\end{array}$ & $\begin{array}{l}\text { TDS } \\
(\mathrm{mg} / \mathrm{L})\end{array}$ & $\begin{array}{l}\text { TSS } \\
(\mathrm{mg} / \mathrm{L})\end{array}$ & $\begin{array}{l}\mathrm{BOD}_{5} \\
(\mathrm{mg} / \mathrm{L})\end{array}$ & $\begin{array}{l}\mathrm{COD} \\
(\mathrm{mg} / \mathrm{L})\end{array}$ \\
\hline & & & & & & & \\
\hline Number of observations & 1835 & 1668 & 864 & 2994 & 3396 & 3110 & 2758 \\
\hline$\%$ of samples above detection & 71.8 & 100 & 100 & 99.5 & 99.6 & 96.2 & 98.3 \\
\hline Median & 4.0 & 7.50 & 16.4 & 80 & 58 & 8.6 & 53 \\
\hline Coefficient of variation & 10.1 & 0.1 & 0.4 & 2.5 & 1.8 & 1.6 & 1.2 \\
\hline \multicolumn{8}{|l|}{ Residential (1069) } \\
\hline Number of observations & 524 & 319 & 205 & 861 & 985 & 935 & 791 \\
\hline$\%$ of samples above detection & 64.5 & 100 & 100 & 99.2 & 99.7 & 97.6 & 98.6 \\
\hline Median & 3.1 & 7.3 & 16.4 & 70.7 & 48 & 9 & 55 \\
\hline Coefficient of variation & 8.0 & 0.1 & 0.4 & 2.0 & 1.8 & 1.5 & 1.1 \\
\hline \multicolumn{8}{|l|}{ Mixed Residential (615) } \\
\hline Number of observations & 255 & 324 & 143 & 477 & 578 & 561 & 448 \\
\hline$\%$ of samples above detection & 74.2 & 100 & 100 & 99.4 & 99.8 & 93.9 & 99.3 \\
\hline Median & 4.0 & 7.50 & 16.0 & 86 & 68 & 7.7 & 42 \\
\hline Coefficient of variation & 2.5 & 0.1 & 0.3 & 2.2 & 1.6 & 1.3 & 1.4 \\
\hline \multicolumn{8}{|l|}{ Commercial (497) } \\
\hline Number of observations & 302 & 165 & 79 & 407 & 452 & 426 & 367 \\
\hline$\%$ of samples above detection & 72.2 & 100 & 100 & 99.5 & 98.9 & 97.4 & 98.4 \\
\hline Median & 4.7 & 7.30 & 16.0 & 77 & 43 & 11.9 & 63 \\
\hline Coefficient of variation & 3.2 & 0.1 & 0.4 & 1.8 & 2.0 & 1.1 & 1.0 \\
\hline \multicolumn{8}{|l|}{ Mixed Commercial (303) } \\
\hline Number of observations & 116 & 137 & 79 & 250 & 280 & 261 & 250 \\
\hline$\%$ of samples above detection & 88.8 & 100 & 100 & 100 & 100 & 99.2 & 99.6 \\
\hline Median & 4.0 & 7.60 & 15.0 & 69 & 54 & 9 & 60 \\
\hline Coefficient of variation & 2.9 & 0.1 & 0.4 & 1.9 & 1.4 & 1.7 & 1.0 \\
\hline \multicolumn{8}{|l|}{ Industrial (524) } \\
\hline Number of observations & 324 & 234 & 140 & 422 & 431 & 407 & 364 \\
\hline$\%$ of samples above detection & 70.7 & 100 & 100 & 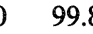 & 99.8 & 95.3 & 98.6 \\
\hline Median & 4.0 & 7.50 & 17.9 & 92 & 77 & 9 & 60 \\
\hline Coefficient of variation & 12.4 & 0.1 & 0.3 & 3.5 & 1.5 & 1.7 & 1.2 \\
\hline
\end{tabular}


Table 13.1. Summary of available stormwater data included in NSQD, version 1.0 (continued)

\begin{tabular}{|c|c|c|c|c|c|c|}
\hline \multirow[b]{2}{*}{ Overall Summary (3770) } & $\begin{array}{l}\text { Fecal } \\
\text { Coliform } \\
(\mathrm{mpn} / 100 \\
\mathrm{mL})\end{array}$ & $\begin{array}{l}\text { Fecal } \\
\text { Strep. } \\
(\mathrm{mpn} / \\
100 \mathrm{~mL})\end{array}$ & $\begin{array}{l}\text { Total } \\
\text { Coliform } \\
(\mathrm{mpn} / \\
100 \mathrm{~mL})\end{array}$ & $\begin{array}{l}\text { Total E. } \\
\text { Coli } \\
(\mathrm{mpn} / \\
100 \mathrm{~mL})\end{array}$ & \multirow[t]{2}{*}{$\begin{array}{l}\mathrm{NH}_{3} \\
(\mathrm{mg} / \mathrm{L})\end{array}$} & $\begin{array}{l}\mathrm{NO}_{2}+\mathrm{NO}_{3} \\
(\mathrm{mg} / \mathrm{L})\end{array}$ \\
\hline & & & & & & \\
\hline Number of observations & 1707 & 1143 & 85 & 67 & 1914 & 3087 \\
\hline$\%$ of samples above detection & 91.2 & 94.0 & 90.6 & 95.5 & 71.7 & 97.4 \\
\hline Median & 5081 & 17000 & 11000 & 1750 & 0.44 & 0.6 \\
\hline Coefficient of variation & 4.61 & 3.8 & 2.4 & 2.3 & 3.6 & 1.1 \\
\hline \multicolumn{7}{|l|}{ Residential (1069) } \\
\hline Number of observations & 440 & 300 & & 14 & 595 & 923 \\
\hline$\%$ of samples above detection & 88.2 & 89.0 & & 100 & 81.3 & 97.6 \\
\hline Median & 7750 & 24000 & & 700 & 0.31 & 0.6 \\
\hline Coefficient of variation & 5.1 & 1.8 & & 1.6 & 1.1 & 1.3 \\
\hline \multicolumn{7}{|l|}{ Mixed Residential (615) } \\
\hline Number of observations & 314 & 158 & 27 & 11 & 263 & 540 \\
\hline$\%$ of samples above detection & 94.9 & 98.1 & 85.2 & 90.9 & 58.6 & 98.1 \\
\hline Median & 11000 & 26000 & 5467 & 1050 & 0.39 & 0.6 \\
\hline Coefficient of variation & 3.3 & 2.2 & 1.4 & 2.1 & 4.4 & 1.0 \\
\hline \multicolumn{7}{|l|}{ Commercial (497) } \\
\hline Number of observations & 228 & 176 & & & 299 & 419 \\
\hline$\%$ of samples above detection & 87.7 & 91.5 & & & 83.3 & 98.1 \\
\hline Median & 4500 & 10800 & & & 0.50 & 0.6 \\
\hline Coefficient of variation & 2.8 & 2.7 & & & 1.2 & 1.1 \\
\hline \multicolumn{7}{|l|}{ Mixed Commercial (303) } \\
\hline Number of observations & 104 & 87 & & & 163 & 273 \\
\hline$\%$ of samples above detection & 94.2 & 98.9 & & & 66.9 & 97.1 \\
\hline Median & 4990 & 11000 & & & 0.60 & 0.6 \\
\hline Coefficient of variation & 3.2 & 2.8 & & & 1.0 & 0.7 \\
\hline \multicolumn{7}{|l|}{ Industrial (524) } \\
\hline Number of observations & 299 & 195 & & & 255 & 415 \\
\hline$\%$ of samples above detection & 88.1 & 93.8 & & & 85.9 & 96.1 \\
\hline Median & 2500 & 13000 & & & 0.50 & 0.7 \\
\hline Coefficient of variation & 5.6 & 6.9 & & & 4.0 & 1.0 \\
\hline
\end{tabular}


Table 13.1. Summary of available stormwater data included in NSQD, version 1.0 (continued)

\begin{tabular}{|c|c|c|c|c|c|c|c|}
\hline \multirow[b]{2}{*}{ Overall Summary (3770) } & $\begin{array}{l}\text { Nitrogen, } \\
\text { Total } \\
\text { Kjeldahl } \\
\text { (mg/L) } \\
\end{array}$ & \multicolumn{2}{|c|}{$\begin{array}{l}\text { Phos., Phos., } \\
\text { filtered total } \\
(\mathrm{mg} / \mathrm{L})(\mathrm{mg} / \mathrm{L})\end{array}$} & $\begin{array}{l}\mathrm{Sb} \\
\text { total } \\
(\mu \mathrm{g} / \mathrm{L})\end{array}$ & $\begin{array}{l}\text { As, } \\
\text { total } \\
(\mu \mathrm{g} / \mathrm{L})\end{array}$ & $\begin{array}{l}\text { As, } \\
\text { filtered } \\
(\mu \mathrm{g} / \mathrm{L})\end{array}$ & $\begin{array}{l}\mathrm{Be}, \\
\text { total } \\
(\mu \mathrm{g} / \mathrm{L}) \\
\end{array}$ \\
\hline & & & & & & & \\
\hline Number of observations & 3199 & 2480 & 3283 & 876 & 1506 & 209 & 948 \\
\hline$\%$ of samples above detection & 96.5 & 86.3 & 96.7 & 7.3 & 57.2 & 27.3 & 7.7 \\
\hline Median & 1.4 & 0.12 & 0.27 & 3.0 & 3.0 & 1.5 & 0.4 \\
\hline Coefficient of variation & 1.4 & 1.6 & 1.5 & 1.7 & 2.4 & 1.0 & 2.5 \\
\hline \multicolumn{8}{|l|}{ Residential (1069) } \\
\hline Number of observations & 951 & 732 & 957 & & 417 & & 292 \\
\hline$\%$ of samples above detection & 97.1 & 84.4 & 96.9 & & 46.0 & & 7.5 \\
\hline Median & 1.4 & 0.17 & 0.30 & & 3.0 & & 0.5 \\
\hline Coefficient of variation & 1.3 & 1.0 & 1.1 & & 2.1 & & 2.5 \\
\hline \multicolumn{8}{|l|}{ Mixed Residential (615) } \\
\hline Number of observations & 529 & 411 & 557 & & 176 & & 88 \\
\hline$\%$ of samples above detection & 95.8 & 83.5 & 96.2 & & 79.0 & & 12.5 \\
\hline Median & 1.3 & 0.12 & 0.27 & & 3.1 & & 0.3 \\
\hline Coefficient of variation & 1.9 & 1.1 & 1.7 & & 3.9 & & 2.7 \\
\hline \multicolumn{8}{|l|}{ Commercial (497) } \\
\hline Number of observations & 443 & 317 & 440 & & 207 & & \\
\hline$\%$ of samples above detection & 97.5 & 81.7 & 95.9 & & 33.3 & & \\
\hline Median & 1.6 & 0.11 & 0.22 & & 2.3 & 3 & \\
\hline Coefficient of variation & 0.9 & 1.3 & 1.2 & & 3.2 & 2 & \\
\hline \multicolumn{8}{|l|}{ Mixed Commercial (303) } \\
\hline Number of observations & 261 & 222 & 273 & 80 & 123 & & \\
\hline$\%$ of samples above detection & 96.9 & 95.1 & 98.6 & 12.5 & 64.2 & & \\
\hline Median & 1.4 & 0.11 & 0.25 & 15.0 & 2.2 & 2 & \\
\hline Coefficient of variation & 0.9 & 2.1 & 1.5 & 1.0 & 1.0 & 0 & \\
\hline \multicolumn{8}{|l|}{ Industrial (524) } \\
\hline Number of observations & 442 & 327 & 437 & 162 & 264 & & 202 \\
\hline$\%$ of samples above detection & 96.4 & 87.2 & 96.3 & 15.4 & 58.0 & & 10.9 \\
\hline Median & 1.4 & 0.11 & 0.26 & 3.4 & 4.0 & 0 & 0.4 \\
\hline Coefficient of variation & 1.2 & 1.2 & 1.4 & 1.4 & 1.4 & 4 & 2.5 \\
\hline
\end{tabular}


Table 13.1. Summary of available stormwater data included in NSQD, version 1.0 (continued)

\begin{tabular}{|c|c|c|c|c|c|c|}
\hline \multirow[b]{2}{*}{ Overall Summary (3770) } & \multirow[t]{2}{*}{$\begin{array}{l}\mathrm{Cd}, \\
\text { total } \\
(\mu \mathrm{g} / \mathrm{L})\end{array}$} & $\begin{array}{l}\mathrm{Cd}, \\
\text { filtered } \\
(\mu \mathrm{g} / \mathrm{L})\end{array}$ & $\begin{array}{l}\mathrm{Cr}, \\
\text { total } \\
(\mu \mathrm{g} / \mathrm{L})\end{array}$ & $\begin{array}{l}\mathrm{Cr}, \\
\text { filtered } \\
(\mu \mathrm{g} / \mathrm{L})\end{array}$ & $\begin{array}{l}\mathrm{Cu}, \\
\text { total } \\
(\mu \mathrm{g} / \mathrm{L})\end{array}$ & $\begin{array}{l}\mathrm{Cu}, \\
\text { filtered } \\
(\mu \mathrm{g} / \mathrm{L})\end{array}$ \\
\hline & & & & & & \\
\hline Number of observations & 2582 & 388 & 1599 & 260 & 2728 & 411 \\
\hline$\%$ of samples above detection & 49.6 & 30.4 & 71.6 & 60.8 & 87.9 & 83 \\
\hline Median & 1.0 & 0.50 & 7.0 & 2.1 & 16 & 8.0 \\
\hline Coefficient of variation & 28.2 & 1.1 & 1.5 & 0.7 & 2.2 & 1.6 \\
\hline \multicolumn{7}{|l|}{ Residential (1069) } \\
\hline Number of observations & 707 & & 426 & & 790 & 90 \\
\hline$\%$ of samples above detection & 35.5 & & 56.1 & & 83.7 & 63.3 \\
\hline Median & 0.5 & & 4.5 & & 12 & 7.0 \\
\hline Coefficient of variation & 1.7 & & 1.4 & & 1.8 & 2.0 \\
\hline \multicolumn{7}{|l|}{ Mixed Residential (615) } \\
\hline Number of observations & 434 & 30 & 184 & 21 & 448 & 29 \\
\hline$\%$ of samples above detection & 49.3 & 40.0 & 83.2 & 52.4 & 84.3 & 72.4 \\
\hline Median & 0.8 & 0.30 & 7.0 & 2.0 & 17 & 5.5 \\
\hline Coefficient of variation & 3.8 & 0.6 & 1.6 & 0.8 & 1.3 & 0.9 \\
\hline \multicolumn{7}{|l|}{ Commercial (497) } \\
\hline Number of observations & 353 & 47 & 230 & 27 & 381 & 48 \\
\hline$\%$ of samples above detection & 46.7 & 23.4 & 60.9 & 40.7 & 93.2 & 79.2 \\
\hline Median & 0.9 & 0.30 & 6.0 & 2.0 & 17 & 7.6 \\
\hline Coefficient of variation & 1.6 & 1.34 & 1.4 & 0.6 & 1.5 & 0.8 \\
\hline \multicolumn{7}{|l|}{ Mixed Commercial (303) } \\
\hline Number of observations & 169 & 24 & 121 & 20 & 173 & 24 \\
\hline$\%$ of samples above detection & 63.9 & 41.7 & 90.1 & 75.0 & 94.8 & 91.7 \\
\hline Median & 0.9 & $0.4 C$ & 4.5 & 2.0 & 17 & 9.5 \\
\hline Coefficient of variation & 1.1 & 0.5 & 1.2 & 0.7 & 3.0 & 0.6 \\
\hline \multicolumn{7}{|l|}{ Industrial (524) } \\
\hline Number of observations & 394 & 42 & 253 & 36 & 415 & 42 \\
\hline$\%$ of samples above detection & 53.8 & 54.8 & 72.7 & 55.6 & 89.9 & 90.5 \\
\hline Median & 2.0 & 0.60 & 14.5 & 3.0 & 22 & 8.0 \\
\hline Coefficient of variation & 2.4 & 1.1 & 1.2 & 0.7 & 2.0 & 0.7 \\
\hline
\end{tabular}


Table 13.1. Summary of available stormwater data included in NSQD, version 1.0 (continued)

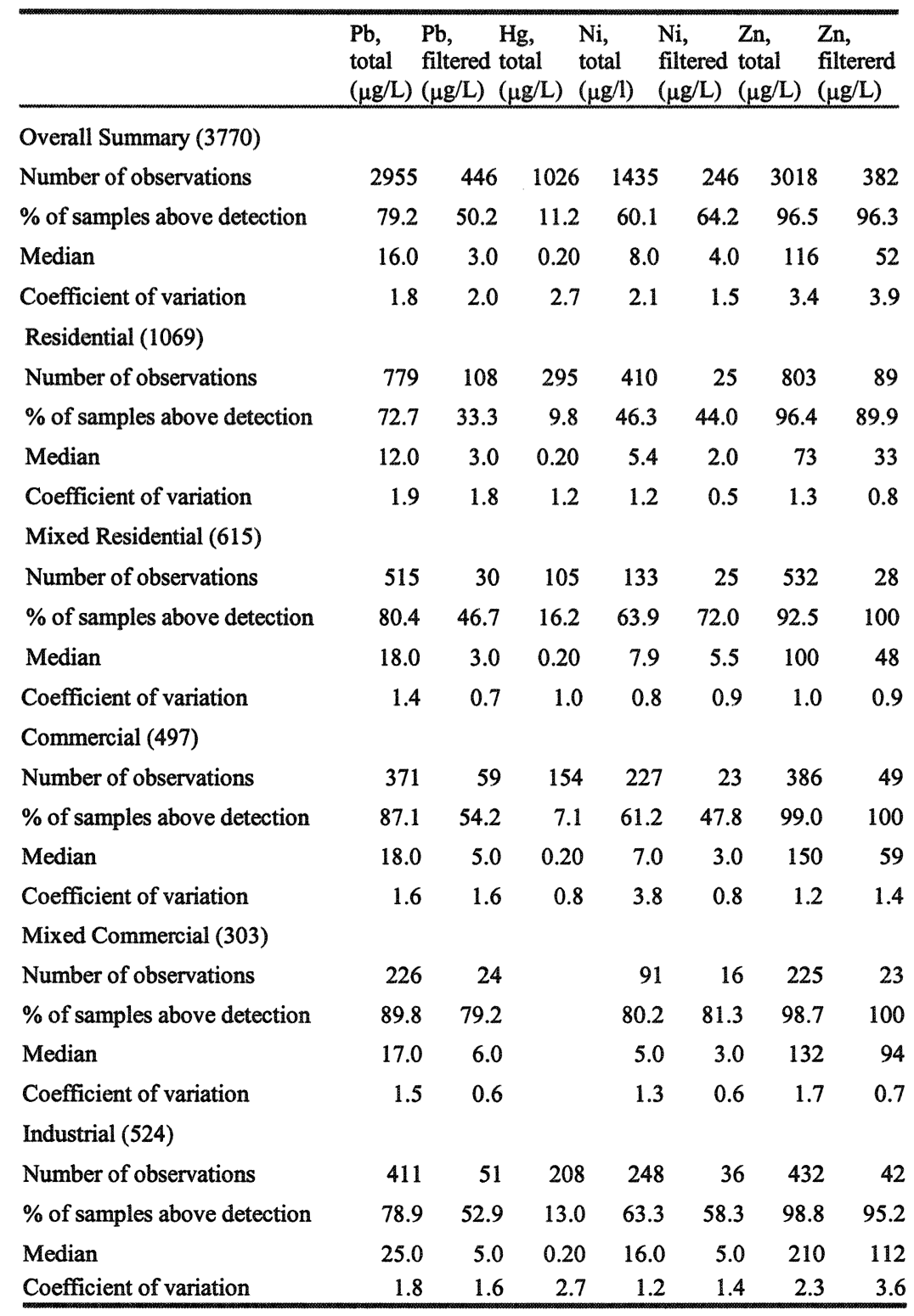


Table 13.1. Summary of available stormwater data included in NSQD, version 1.0 (continued)

\begin{tabular}{|c|c|c|c|c|c|c|}
\hline & $\begin{array}{c}\text { Area } \\
\text { (acres) }\end{array}$ & $\begin{array}{ll} & \mathbf{P} \\
\% & \mathrm{D} \\
\text { Imperv. (i }\end{array}$ & $\begin{array}{l}\text { Precip. } \\
\text { Depth I } \\
\text { (in) }\end{array}$ & $\begin{array}{l}\text { Runoff } \\
\text { Depth } \\
\text { (in) }\end{array}$ & $\begin{array}{l}\text { Cond. } \\
\text { (uS/cm } \\
\left.@ 25^{\circ} \mathrm{C}\right)\end{array}$ & $\begin{array}{l}\text { Hardness } \\
\text { (mg/L } \\
\mathrm{CaCO} 3 \text { ) } \\
\end{array}$ \\
\hline \multicolumn{7}{|l|}{ Mixed Industrial (252) } \\
\hline Number of observations & 252 & 133 & 226 & 117 & 58 & 83 \\
\hline$\%$ of samples above detection & 100 & 100 & 100 & 100 & 100 & 94.0 \\
\hline Median & 127.7 & 44.0 & 0.45 & 0.29 & 111 & 33.0 \\
\hline Coefficient of variation & 2.0 & 0.3 & 0.8 & 1.2 & 0.8 & 0.5 \\
\hline \multicolumn{7}{|l|}{ Institutional (18) } \\
\hline Number of observations & 18 & 18 & 17 & 14 & & \\
\hline$\%$ of samples above detection & 100 & 100 & 100 & 100 & & \\
\hline Median & 36.0 & 45.0 & 0.18 & 0.00 & & \\
\hline Coefficient of variation & $<0.1$ & 0.2 & 0.9 & 2.1 & & \\
\hline \multicolumn{7}{|l|}{ Freeways (185) } \\
\hline Number of observations & 185 & 154 & 182 & 144 & 86 & 128 \\
\hline$\%$ of samples above detection & 100 & 100 & 100 & 100 & 100 & 99.2 \\
\hline Median & 1.6 & 80.0 & 0.54 & 0.41 & 99 & 34.0 \\
\hline Coefficient of variation & 1.4 & 0.13 & 1.0 & 1.7 & 1.0 & 1.9 \\
\hline \multicolumn{7}{|l|}{ Mixed Freeways (20) } \\
\hline Number of observations & 20 & & 20 & & 13 & 12 \\
\hline$\%$ of samples above detection & 100 & & 100 & & 100 & 100 \\
\hline Median & 63.1 & & 0.68 & & 418 & 83 \\
\hline Coefficient of variation & $<0.1$ & & 0.6 & & 0.6 & 0.3 \\
\hline \multicolumn{7}{|l|}{ Open Space (68) } \\
\hline Number of observations & 68 & 34 & 60 & 22 & 23 & 28 \\
\hline$\%$ of samples above detection & 100 & 100 & 100 & 100 & 100 & 100 \\
\hline Median & 73.5 & 2.0 & 0.48 & 0.17 & 155 & 117 \\
\hline Coefficient of variation & 1.8 & 1.3 & 1.1 & 1.3 & 0.7 & 0.6 \\
\hline \multicolumn{7}{|l|}{ Mixed Open Space (159) } \\
\hline Number of observations & 159 & 89 & 158 & 61 & 62 & 50 \\
\hline$\%$ of samples above detection & 100 & 100 & 100 & 100 & 100 & 100 \\
\hline Median & 115.4 & 34.0 & 0.43 & 0.12 & 215 & 55.0 \\
\hline Coefficient of variation & 0.9 & 0.14 & 0.9 & 1.2 & 1.8 & 1.5 \\
\hline
\end{tabular}


Table 13.1. Summary of available stormwater data included in NSQD, version 1.0 (continued)

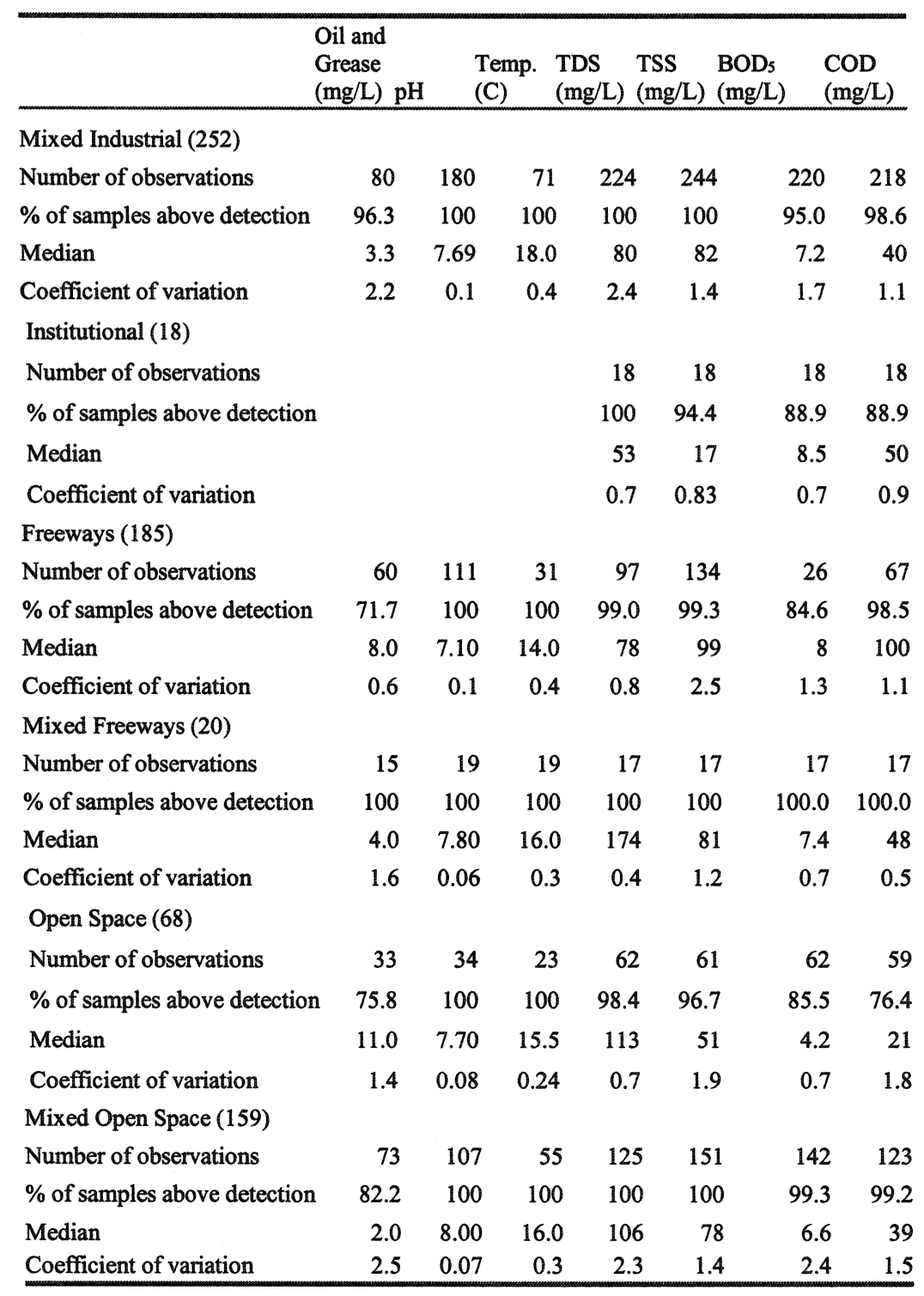


Table 13.1. Summary of available stormwater data included in NSQD, version 1.0 (continued)

\begin{tabular}{|c|c|c|c|c|c|c|}
\hline & $\begin{array}{ll}\text { Fecal } & F \\
\text { Coliform } & S \\
(\mathrm{mpn} / & \\
100 \mathrm{~mL}) & 1 \\
\end{array}$ & $\begin{array}{l}\text { Fecal } \\
\text { Strep. } \\
(\mathrm{mpn} / \\
100 \mathrm{~mL}) \\
\end{array}$ & $\begin{array}{l}\text { Total } \\
\text { Coliform } \\
(\mathrm{mpn} / \\
100 \mathrm{~mL}) \\
\end{array}$ & $\begin{array}{l}\text { Total E. } \\
\text { Coli } \\
(\mathrm{mpn} / \\
100 \mathrm{~mL}) \\
\end{array}$ & $\begin{array}{l}\mathrm{NH}_{3} \\
(\mathrm{mg} / \mathrm{L})\end{array}$ & $\begin{array}{l}\mathrm{NO}_{2}+\mathrm{NO}_{3} \\
(\mathrm{mg} / \mathrm{L})\end{array}$ \\
\hline \multicolumn{7}{|l|}{ Mixed Industrial (252) } \\
\hline Number of observations & 115 & 70 & 40 & & 125 & 214 \\
\hline$\%$ of samples above detection & 95.7 & 97.1 & 90.0 & & 31.2 & 98.6 \\
\hline Median & 3033 & 10000 & 12500 & & 0.43 & 0.56 \\
\hline \multicolumn{7}{|l|}{ Institutional (18) } \\
\hline Number of observations & & & & & 18 & 18 \\
\hline$\%$ of samples above detection & & & & & 88.9 & 100 \\
\hline Median & & & & & 0.31 & 0.6 \\
\hline Coefficient of variation & & & & & 0.5 & 0.6 \\
\hline \multicolumn{7}{|l|}{ Freeways (185) } \\
\hline Number of observations & 49 & 25 & 16 & 13 & 79 & 25 \\
\hline$\%$ of samples above detection & 100 & 100 & 100 & 100 & 87.3 & 96.0 \\
\hline Median & 1700 & 17000 & 50000 & 1900 & 1.07 & 0.3 \\
\hline Coefficient of variation & 1.9 & 1.2 & 1.5 & 2.2 & 1.3 & 1.2 \\
\hline \multicolumn{7}{|l|}{ Mixed Freeways (20) } \\
\hline Number of observations & 16 & 12 & & & & 14 \\
\hline$\%$ of samples above detection & 81.3 & 93.8 & & & & 100 \\
\hline Median & 730 & 19000 & & & & 0.6 \\
\hline Coefficient of variation & 2.0 & 1.1 & & & & 0.7 \\
\hline \multicolumn{7}{|l|}{ Open Space (68) } \\
\hline Number of observations & 37 & 37 & & & 35 & 58 \\
\hline$\%$ of samples above detection & 94.6 & 94.6 & & & 22.9 & 88.5 \\
\hline Median & 3100 & 24000 & & & 0.30 & 0.6 \\
\hline Coefficient of variation & 2.9 & 2.6 & & & 1.1 & 0.86 \\
\hline \multicolumn{7}{|l|}{ Mixed Open Space (159) } \\
\hline Number of observations & 75 & 55 & & & 65 & 150 \\
\hline$\%$ of samples above detection & 97.3 & 100 & & & 20.6 & 97.3 \\
\hline Median & 3249 & 21000 & & & 0.51 & 0.7 \\
\hline Coefficient of variation & 2.1 & 2.3 & & & 1.17 & 0.94 \\
\hline
\end{tabular}


Table 13.1. Summary of available stormwater data included in NSQD, version 1.0 (continued)

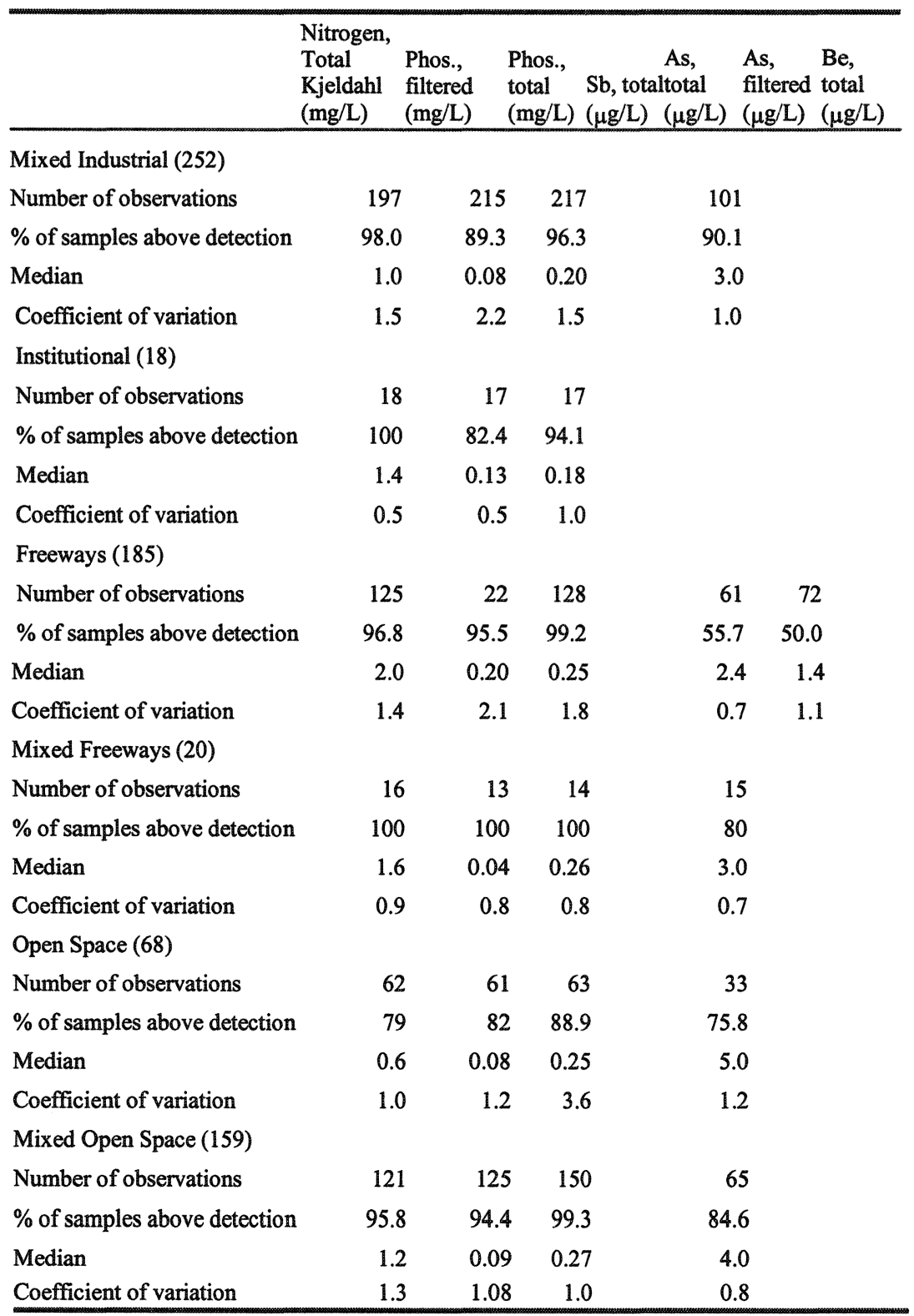


Table 13.1. Summary of available stormwater data included in NSQD, version 1.0 (continued)

$\mathrm{Cd}, \mathrm{Cd}, \mathrm{Cr}, \mathrm{Cr}, \mathrm{Cu}, \mathrm{Cu}$, total filtered total filtered total filtered

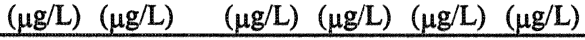

\begin{tabular}{|c|c|c|c|c|c|c|}
\hline \multicolumn{7}{|l|}{ Mixed Industrial (252) } \\
\hline Number of observations & 183 & 25 & 124 & 15 & 183 & 24 \\
\hline$\%$ of samples above detection & 66.7 & 92.0 & 93.5 & 66.7 & 88.0 & 100.0 \\
\hline Median & 1.0 & 0.60 & 8.0 & 2.0 & 17 & 6.0 \\
\hline Coefficient of variation & 10.9 & 0.6 & 1.7 & 0.7 & 0.9 & 0.6 \\
\hline \multicolumn{7}{|l|}{ Institutional (18) } \\
\hline \multicolumn{7}{|l|}{ Number of observations } \\
\hline \multicolumn{7}{|l|}{$\%$ of samples above detection } \\
\hline \multicolumn{7}{|l|}{ Median } \\
\hline \multicolumn{7}{|l|}{ Coefficient of variation } \\
\hline \multicolumn{7}{|l|}{ Freeways (185) } \\
\hline Number of observations & 95 & 114 & 76 & 101 & 97 & 130 \\
\hline$\%$ of samples above detection & 71.6 & 26.3 & 98.7 & 78.2 & 99.0 & 99.2 \\
\hline Median & 1.0 & 0.68 & 8.3 & 2.3 & 35 & 10.9 \\
\hline Coefficient of variation & 0.9 & 1.0 & 0.7 & 0.7 & 1.0 & 1.5 \\
\hline \multicolumn{7}{|l|}{ Mixed Freeways (20) } \\
\hline Number of observations & 15 & & 15 & & 17 & \\
\hline$\%$ of samples above detection & 80 & & 100 & & 94 & \\
\hline Median & 0.5 & & 6.0 & & 8.5 & \\
\hline Coefficient of variation & 0.7 & & 1.1 & & 1.1 & \\
\hline \multicolumn{7}{|l|}{ Open Space (68) } \\
\hline Number of observations & 55 & & 50 & & 56 & \\
\hline$\%$ of samples above detection & 65.4 & & 60 & & 84 & \\
\hline Median & 0.5 & & 5.0 & & 5.3 & \\
\hline Coefficient of variation & 1.7 & & 2.1 & & 2.2 & \\
\hline \multicolumn{7}{|l|}{ Mixed Open Space (159) } \\
\hline Number of observations & 102 & & 65 & & 100 & \\
\hline$\%$ of samples above detection & 51 & & 87.7 & & 93 & \\
\hline Median & 1.0 & & 5.0 & & 11 & \\
\hline Coefficient of variation & 1.9 & & 1.5 & & 1.5 & \\
\hline
\end{tabular}


Table 13.1. Summary of available stormwater data included in NSQD, version 1.0 (continued)

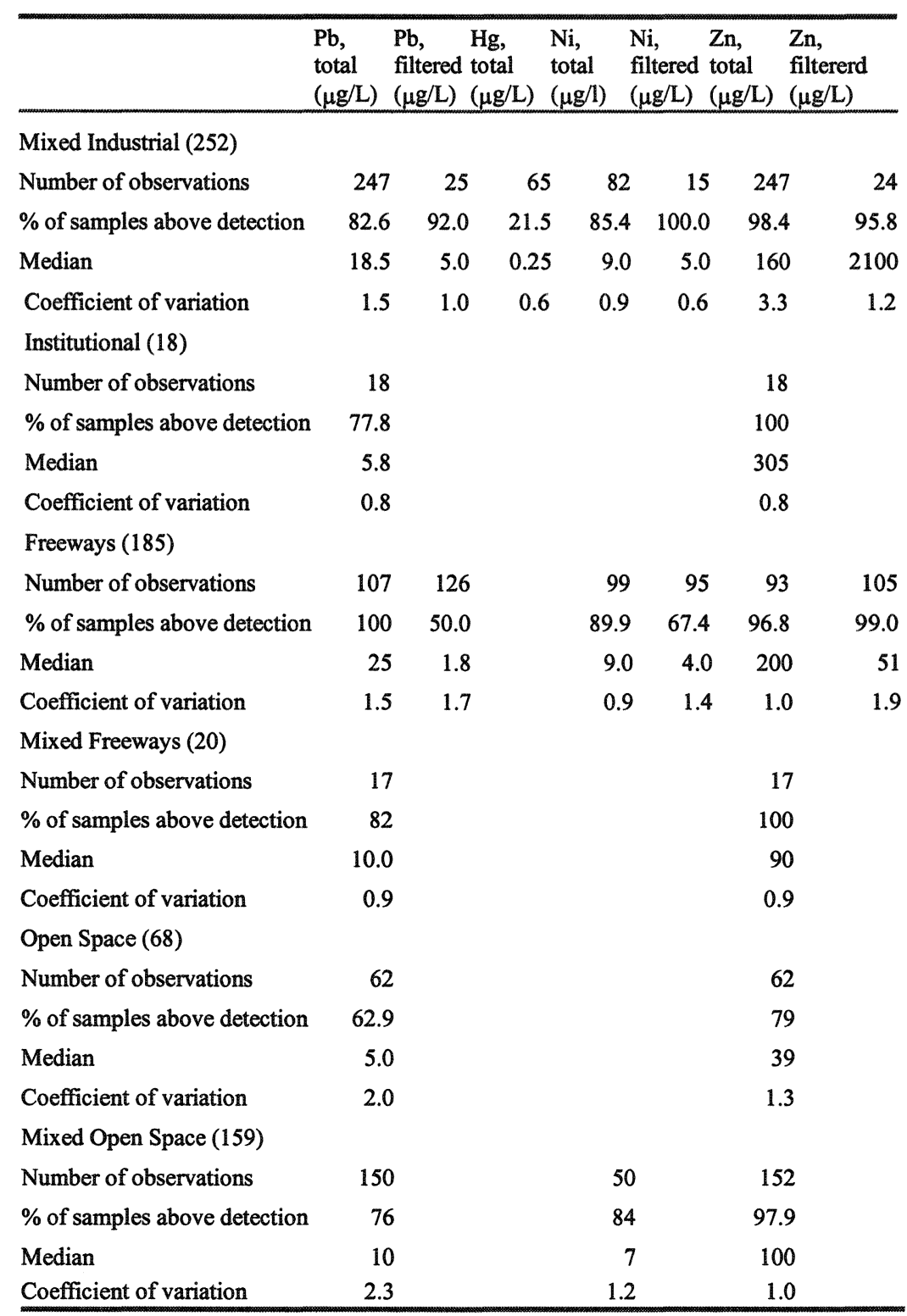




\section{References}

Auckland Regional Council. Annual Report. January-December 2001 Baseline Water Quality. Streams, Lake, and Saline Waters. Technical Publication 190. August 2002.

Bertrand-Krajewski, J. "Distribution of Pollutant Mass vs. Volume in Stormwater Discharges and the First Flush Phenomenon". Water Resources, Vol 32, No. 8 pp. 2341-2356. 1998.

Burton, G.A. Jr., and R. Pitt, Stormwater Effects Handbook: A Tool Box for Watershed Managers, Scientists, and Engineers. CRC Press, Inc., Boca Raton, FL. 911 pgs. 2002.

Clark, S., R. Pitt, and S. Burian. "Urban Wet Weather Flows - 2002 Literature Review." Water Environment Research. Vol. 75, No. 5, Sept./Oct. 2003 (CD-ROM).

Clark, S., R. Pitt, and S. Burian. "Urban Wet Weather Flows - 2001 Literature Review." Water Environment Research. Vol. 74, No. 5, Sept./Oct. 2002 (CD-ROM).

Clark, S., R. Rovansek, L. Wright, J. Heaney, R. Field, and R. Pitt. "Urban Wet Weather Flows - 2000 Literature Review." Water Environment Research. Vol. 73, No. 5, Sept./Oct. 2001 (CD-ROM).

Deletic, A. "The First Flush Load of Urban Surface Runoff". Water Resources, Vol 32, No 8, pp. 2462-2470, 1998.

Fan, C-Y, R. Field, J. Heaney, R. Pitt, S. Clark, L. Wright, R. Rovansek, and S. Olivera. "Urban Wet Weather Flows 1999 Literature Review." Water Environment Research. Vol. 72, No. 5, Sept./Oct. 2000 (CD-ROM), 199 pgs.

Field, R., T. O'Connor, C-Y. Fan, R. Pitt, S. Clark, J. Ludwig, and T. Hendrix. "Urban Wet Weather Flows - 1997 Literature Review." Water Environment Research. Vol. 70, No. 4, June 1998.

Field, R., R. Pitt, Hsu, K., M. Borst, R. DeGuida, C-Y. Fan, J. Heaney, J. Perdek, and M. Stinson. "Urban Wet Weather Flow - 1996 Literature Review." Water Environment Research. Vol. 69, No. 4, pp. 426-444. June 1997.

Fligner M. Policello, G. "Robust Rank Procedures for the Behrens-Fisher Problem". Journal of the American Statistical Association, Volume 76, Issue 373. pp 162-168. 1981.

Maestre, A., R.E. Pitt and D. Williamson. 2004. "Nonparametric Statistical Tests Comparing First Flush and Composite Samples from the National Stormwater Quality Database." Journal of Water Management Modeling R220-15. doi: 10.14796/JWMM.R220-15.

O’Connor, R. Field, D. Fischer, R. Rovansek, R. Pitt, S. Clark, and M. Lama. "Urban Wet Weather Flows - 1998 Literature Review." Water Environment Research. Vol. 71, No. 4, June 1999.

Pitt, R., R. Field, M. Lalor, and M. Brown. "Urban Stormwater Toxic Pollutants: Assessment, Sources and Treatability." Water Environment Research. Vol. 67, No. 3, pp. 260-275. May/June 1995. 
Pitt, R., M. Lalor, R. Field, D.D. Adrian, and D. Barbe'. A User's Guide for the Assessment of Non-Stormwater Discharges into Separate Storm Drainage Systems. U.S. Environmental Protection Agency, Storm and Combined Sewer Program, Risk Reduction Engineering Laboratory. EPA/600/R-92/238. PB93131472. Cincinnati, Ohio. 87 pgs. January 1993.

Pitt, R. Maestre A., Morquecho R. "Evaluation of NPDES phase I Municipal Stormwater Monitoring Data" In: National Conference on Urban Stormwater: Enhancing the Programs at the Local Level. EPA/625/R-03/003. February 2003

Roa-Espinosa A. Bannerman, R. "Monitoring BMP effectiveness at Industrial Sites". In: Stormwater NPDES Related Monitoring Needs. Edited by Harry C. Torno. pp 467-486. 1995.

Smullen, J.T. and K.A. Cave, "National stormwater runoff pollution database." In: Wet-Weather Flow in the Urban Watershed, edited by R. Field and D. Sullivan. Lewis Publishers. Boca Raton, pgs. 67 - 78. 2002.

U.S. Environmental Protection Agency, Dec. Results of the Nationwide Urban Runoff Program. Water Planning Division, PB 84-185552, Washington, D.C. 1983. 